\title{
Monetary Policy and Output Growth Forecasting in a SVAR Perspective
}

\author{
Adebayo Augustine Kutu ${ }^{1}$, Gbenga Wilfred Akinola ${ }^{1} \&$ Ntokozo Patrick Nzimande ${ }^{1}$ \\ ${ }^{1}$ School of Accounting, Economics and Finance, University of KwaZulu-Natal, Durban, South Africa \\ Correspondence: Adebayo Augustine Kutu, School of Accounting, Economics and Finance, University of \\ KwaZulu-Natal, Westville Campus, Durban 4000, South Africa. E-mail: ade_kutu@ yahoo.com
}

Received: April 1, 2016

Accepted: April 29, 2016

Online Published: June 25, 2016

doi:10.5539/ijef.v8n7p71

URL: http://dx.doi.org/10.5539/ijef.v8n7p71

\begin{abstract}
This paper presents a short-term forecasting model of monthly South African macroeconomic variables to estimate the effects of monetary policy on output growth from a Structural Vector Autoregression (SVAR) perspective. A set of forecasting experimentations are carried out to evaluate the out-of-sample static and dynamic forecast for the post-apartheid period. We carried out a combined forecast in order to compare the static with dynamic forecasting approach for improving output growth. The findings reveal that money supply is observed to exert a significant positive impact on output growth from about the eighth month. In addition, the dynamic forecasting is observed to have a more robust result and outperforms the static forecasting. It clearly brings out the growth patterns (increase and decrease) and can be justified and recommended to policymakers in calculating or in predicting the outcome of monetary policy actions for future development. However, in order to improve the predictive forecasting accuracy, the study recommends combined forecasting as dynamic forecasting is associated with risk and uncertainty that is central to its prediction and expected reliability.
\end{abstract}

Keywords: monetary policy, output growth forecasting, structural VARs

\section{Introduction}

Generally, many studies have used time series macroeconomic variables to forecast output growth using low-dimensional methods such as Generalized Method of Moments (GMM), Vector Autoregression (VAR) and Single-equation Regression among others. These low-dimensional methods omit thousands of important variables that are available to economic forecasters due to constraints in accommodating a large number of variables. They are further constrained by degree of freedoms. However, to ensure forecast accuracy and good predictive power of a model, one needs to impose adequate restrictions so that the number of estimated parameters is kept small (Stock \& Watson, 2004). One way to impose such restrictions and employ a high-dimensional system is to assume that the variables have a dynamic factor structure model. Stock and Watson (2002) and Forni et al. (2003) suggest that there are potential gains from forecasting using high-dimensional dynamic factor structural models. This context furnishes this study with two objectives. First, the study aims to estimate the effects of monetary policy on output growth in South Africa using a Structural Vector Autoregression (SVAR) model. The second objective is to forecast the time series data used in the model and determine the predictive power and accuracy of the SVAR model. After an extensive review of the literature, there is, to the best of the researchers' knowledge, no study that has estimated monetary policy and output growth in South Africa as well as those employing a SVAR model.

The monetary policy linkage of the South African economy arises from the interdependence of the financial sector and the industrial sector for meeting the needs of productive input and output to boost investment. The impact of funds supplied by the financial sector increases industrial production, while the interest paid on those funds increases the money growth that the financial institution is able to supply to the economy.

However, natural rate models suggest that monetary policy will not have a significant impact on the business cycle in stimulating economic activity with respect to output and employment in the long run (see Sargent \& Wallace, 1975; Barro \& Gordon, 1983). Their view is that there is a limited effect of monetary policy on output growth. Ping (2004) carried out a study in China and found evidence for the existence of long run monetary neutrality in stimulating output growth and employment (monetary authority mandates is to stabilize prices). Nevertheless, it is observed that an increase in monetary growth provides incentives to monetary authorities to 
pursue countercyclical policies. These in turn promote the goals of maximum employment, stable prices, and moderate long-term interest rates. This behaviour is consistent with the rational expectation that when prices are stable, belief is likely to remain that the prices of goods, services, materials and labour are undistorted by inflation and serve as strong signals and guides for the efficient allocation of resources and boosting of investments, inadvertently contributing to higher standards of living. The view that there is a monetary policy linkage to stimulating output growth further motivated us to estimate the effects of monetary policy on output growth from a SVAR perspective and also determine the predictive accuracy of the model.

In addition to monetary policy linkages to stimulating output growth, the pursuit of output growth and stable prices fosters savings and capital formation, which encourages households and businesses to increase their investments. Goodfriend's (1997) study provides a meticulous analysis explaining the role of quantitative monetary expansion for effective monetary policy that can have an important effect on real economic activities. An effective monetary policy system will lead to an increase in the capacity of an economy to produce goods and services, and consequently lead to qualitative changes in the economy via output growth and employment generation.

Conversely, the optimum monetary policy linkage between interest rates and money supply rules in promoting output growth and sustainable development has also become a topic of lively interest. The interest centres on the use of interest rates and money supply to stimulate the economy. Taylor $(1997$, p. 36) points out that deflation in Japan "made an interest rate rule unreliable, calling for greater emphasis on money supply rules". Friedman (1997), Hayashi (1998) and Meltzer (1998) provide recent reports along these lines for money supply as the optimum monetary policy rule. Woodford (2001) holds an opposing view and believes that an optimal rule will generally involve a commitment to history-dependent behaviour; in particular, a more gradual adjustment of the level of interest rates has important advantages in stimulating output growth. Orphanides and Wieland (2000) discuss along these lines how monetary policy may continue to use interest rate instruments on an operational level, if that is deemed more appropriate by the central bank, and optimal interest rates respond to inflation. However, if both rules are applied together, the process of sustainable development that the monetary authorities are aiming to achieve, especially when targeting output growth and price stability, will be fast-tracked.

\section{The Instruments of Policy and Targets by Monetary Authorities}

According to Mishkin (2007), all central banks pursue a different strategy in the conduct of monetary policy by aiming at a variable that falls within its tools to achieve as its goal. Having decided on the goal needed to stimulate output and price, the policy maker then selects from existing tools to achieve those goals. The central bank chooses a target known as an intermediate target (such as a short/long-term interest rate and monetary aggregate) that has a direct effect on the monetary policy goal (stimulating output and prices). However, if these targets are not directly affected by the central bank's tools, then it chooses another target known as the operating target (Mishkin, 2007). According to Mishkin, the monetary policy authorities use monetary policy tools, which may not affect monetary policy goals directly. Rather, they affect intermediate targets or the operating targets of monetary policy. The term intermediate target is used to differentiate between the monetary authorities' targets drawn from the ultimate monetary goal variables (such as the unemployment rate, inflation rate, growth rate of output, price stability, interest rates and the stability of the financial markets), and the operating variables such as the central bank's reserves and the federal fund rates', which are more responsive to policy tools.

A reserve bank employs the strategy of pursuing intermediate and operating targets because it is easier to achieve a goal by aiming at a target, than by aiming at a goal directly. Aiming directly at a goal can be disastrous if a reserve bank waits to see what the output and price level will be after a specific period (say one year) and this is not achieved. Therefore, through its operating tools, the South African Reserve Bank (SARB), for example, can stimulate output growth and achieve price stability in the country.

\section{Methodology}

Since this study attempts to estimate the effects of monetary policy on industrial output growth in South Africa using a SVAR approach, the brief description of the methodology that is used is described in this section. The SVAR model is a multivariate and linear representation of a vector of observable variables on its own lags. All the observable variables are assumed to be endogenous and interdependent, except for those identified as exogenous. In addition, the model is an economically interpretable simplification of the VAR model, where the structural identification (factorization) restrictions are used in line with some economic theory.

\subsection{SVAR Framework}

The SVAR in this study is estimated using six endogenous variables, namely, Industrial Output (IP), Aggregate 
Output (AG), Exchange Rate (EX), Inflation Rate (IF), Interest Rate (IN) and Money Supply (MS) and two exogenous variables, namely, the global Commodity Price (COMM) and the global Oil Price (OP).

Supposing the South African economy can be denoted by the following structural equation:

$$
A Y_{t}=\alpha_{0}+A_{1}^{*} Y_{t-1}+\cdots \ldots \ldots+A_{p}^{*} Y_{t-p}+B_{0}^{*} X_{t}+\cdots \ldots .+B_{q}^{*} X_{t-q}+B \varepsilon_{t}
$$

where $A$ is an invertible $(8 \times 8)$ matrix describing the contemporaneous relationship among the variables; $Y_{t}$ is a $(8 \times 1)$ vector of endogenous variables such that $Y_{t}=Y_{1 t}, Y_{2 t}, \ldots Y_{n t} . \alpha_{0}$ is a $(8 \times 1)$ vector of constant terms; $A_{1}^{*}-A_{p}^{*}$ is a $(8 \times 8)$ matrix of coefficients of lagged endogenous variables(for every $\left.i=1 \ldots p\right)$; $B_{0}^{*}-B_{q}^{*}$ and $X_{t} \ldots X_{t-q}$ are coefficients and vectors of lagged exogenous variables, respectively, capturing external shocks; $B$ is a $(8 \times 8)$ matrix whose non-zero off-diagonal elements allow for direct effects of some shocks on more than one endogenous variable in the system; and $\varepsilon_{i t}$ is a vector of white-noise structural disturbances (uncorrelated error terms).

Sharifi-Renani (2010) argues that the point of departure for a structural analysis is a reduced form model that has to be specified before the $S V A R$ analysis can be entered. Therefore, equation 1 has to be transformed into a reduced form by pre-multiplying it by an inverse of $A$ in line with Ngalawa and Viegi (2011) as:

$$
A^{-1} A Y_{t}=A^{-1} \alpha_{0}+A^{-1} A_{1}^{*} Y_{t-1}+\cdots \ldots \ldots+A^{-1} A_{p}^{*} Y_{t-p}+A^{-1} B_{0}^{*} X_{t}+\cdots \ldots .+A^{-1} B_{q}^{*} X_{t-q}+A^{-1} B \varepsilon_{t}
$$

This gives:

$$
Y_{t}=A^{-1} \alpha_{0}+A^{-1} A_{1}^{*} Y_{t-1}+\cdots+A^{-1} A_{p}^{*} Y_{t-p}+A^{-1} B_{0}^{*} X_{t}+\cdots \cdot+A^{-1} B_{q}^{*} X_{t-q}+A^{-1} B \varepsilon_{t}
$$

One can denote:

$$
A^{-1} \alpha_{0}=\beta_{0}, A^{-1} A_{1}^{*}=A_{i} \text { for every } i=1 \ldots ., A^{-1} B_{0}^{*}=\alpha_{i} \text { for every } i \ldots . q \text { and } A^{-1} B \varepsilon_{t}=\mu_{t}
$$

Hence, equation 3 becomes:

$$
Y_{t}=\beta_{0}+A_{1} Y_{t-1}+\cdots+A_{p} Y_{t-p}+\alpha_{1} X_{t}+\cdots \cdot+\alpha_{q} X_{t-q}+\mu_{t}
$$

The variance between equations (1) and (4) is that the first is called a long form SVAR that cannot be estimated directly due to the feedback inherent in the VAR process (Enders, 2004) as the endogenous variables have a contemporaneous (immediate) effect on each other in the current and past realization time path of $A Y_{t}$. Equation 4 is called a reduced form $S V A R$ in which no variable has a direct contemporaneous (immediate) effect on another in the model. Additionally, the error term $\left(\mu_{t}\right)$ is a composite of shocks in $Y_{t}$ (Enders, 2004).

Note that equation 4 can be splitting as:

$$
\begin{gathered}
Y_{t}=I P, A G, E X, I F, I N \text { and } M S \\
X_{t}=C O M M \text { and } O P \\
\left(\begin{array}{cccccccc}
1 & 0 & 0 & 0 & 0 & 0 & 0 & 0 \\
\alpha_{21} & 1 & 0 & 0 & 0 & 0 & 0 & 0 \\
\alpha_{31} & 0 & 1 & 0 & 0 & 0 & 0 & \alpha_{38} \\
\alpha_{41} & 0 & \alpha_{43} & 1 & 0 & 0 & 0 & 0 \\
0 & 0 & \alpha_{53} & \alpha_{54} & 1 & \alpha_{56} & 0 & 0 \\
\alpha_{61} & \alpha_{62} & 0 & 0 & \alpha_{65} & 1 & \alpha_{67} & 0 \\
\alpha_{71} & \alpha_{72} & \alpha_{73} & \alpha_{74} & \alpha_{75} & \alpha_{76} & 1 & 0 \\
0 & 0 & 0 & 0 & \alpha_{85} & \alpha_{86} & 0 & 1
\end{array}\right)\left(\begin{array}{c}
\mu_{t}^{\log O P} \\
\mu_{t}^{\log \operatorname{com} M} \\
\mu_{t}^{\log I P} \\
\mu_{t}^{\log A G} \\
\mu_{t}^{\log I F} \\
\mu_{t}^{\log M S} \\
\mu_{t}^{E X} \\
\mu_{t}^{I N}
\end{array}\right)=\left(\begin{array}{c}
\varepsilon_{t}^{\log O P} \\
\varepsilon_{t}^{\log \log M} \\
\varepsilon_{t}^{\log I P} \\
\varepsilon_{t}^{\log A G} \\
\varepsilon_{t}^{\log I F} \\
\varepsilon_{t}^{\log M S} \\
\varepsilon_{t}^{E X} \\
\varepsilon_{t}^{I N}
\end{array}\right)
\end{gathered}
$$

The terms $\mu_{t}^{\log O P}, \mu_{t}^{\log C O M M}, \mu_{t}^{\log I P}, \mu_{t}^{\log A G}, \mu_{t}^{\log I F}, \mu_{t}^{\log M S}, \mu_{t}^{E X}$ and $\mu_{t}^{I N}$ are residuals in the reduced form disturbances to both the domestic and foreign variables and further represent unexpected movements (given information in the system) of each variable; and $\varepsilon_{t}^{\log O P}, \varepsilon_{t}^{\log \operatorname{com} M}$, $\varepsilon_{t}^{\log I P}, \varepsilon_{t}^{\log A G}, \varepsilon_{t}^{\log I F}, \varepsilon_{t}^{\log M S}, \varepsilon_{t}^{E X}$ and $\varepsilon_{t}^{I N}$ are the structural shocks associated with the respective equations.

\subsection{The Identification Restrictions}

The SVAR methodology suggests the imposition of restrictions on the contemporaneous structural parameters 
only for reasonable economic structures to be derived. The work of Buckle et al. (2007) sets the foundation for the traditional SVAR that forms the hybrid approach to structural identification. The main adjustments to the Buckle et al. (2002) model contain the incorporation of identifications to which restrictions' methodology is applied. The restrictions restrict attention to rotations that produces shocks that satisfy an anticipated sign in the responses of key variables (see Dungey \& Fry, 2009). The traditional restrictions are denoted by "NA" (referred as $\alpha i j$ in equation 5) and "0" for the contemporaneous and sluggish lagged relationships, respectively. A total of 36 zero restrictions were imposed on matrix A, which makes the covariance matrix of the reduced-form residuals restricted. The matrix A is the finite-order lag polynomial matrix that clearly demonstrates how the structural restrictions are being estimated with the diagonal constrained to be "1" and the B matrix is the diagonal matrix that is orthogonal (uncorrelated). Eight by eight matrices are formed using the AB-model of Amisano and Gianini $(1997,2012)$ to impose short run structural restrictions on the model given as:

$$
\mathrm{A}=\left[\begin{array}{cccccccc}
1 & 0 & 0 & 0 & 0 & 0 & 0 & 0 \\
N A & 1 & 0 & 0 & 0 & 0 & 0 & 0 \\
N A & 0 & 1 & 0 & 0 & 0 & 0 & N A \\
N A & 0 & N A & 1 & 0 & 0 & 0 & 0 \\
0 & 0 & N A & N A & 1 & N A & 0 & 0 \\
N A & N A & 0 & 0 & N A & 1 & N A & 0 \\
N A & N A & N A & N A & N A & N A & 1 & 0 \\
0 & 0 & 0 & 0 & N A & N A & 0 & 1
\end{array}\right] \quad \mathrm{B}=\left[\begin{array}{cccccccc}
N A & 0 & 0 & 0 & 0 & 0 & 0 & 0 \\
0 & N A & 0 & 0 & 0 & 0 & 0 & 0 \\
0 & 0 & N A & 0 & 0 & 0 & 0 & 0 \\
0 & 0 & 0 & N A & 0 & 0 & 0 & 0 \\
0 & 0 & 0 & 0 & N A & 0 & 0 & 0 \\
0 & 0 & 0 & 0 & 0 & N A & 0 & 0 \\
0 & 0 & 0 & 0 & 0 & 0 & N A & 0 \\
0 & 0 & 0 & 0 & 0 & 0 & 0 & N A
\end{array}\right]
$$

\subsection{Data and Data Sources}

The model consists of eight monthly time series data spanning a period of twenty years from 1994:1 to 2013:12. The study's starting period is the post-apartheid period and the cut-off dates are dictated by data availability. The data are obtained from the South African Reserve Bank (SARB), Statistics South Africa (Stat SA), World Bank's World Development Indicators (WDI) and the Quantec Database. The Aggregate Output Production (AG) (without industrial output production (i.e., GDP minus IP)) and Industrial Output Production (IP) represent the domestic activity and characterize the goods market in the economy. M2 is the Money Supply (MS) and captures the monetary aggregate while Exchange Rates (EX) is the official Rand to Dollar exchange rate as fixed by the Reserve Bank. They both represent our policy variables. The Interest Rate (IN) is the repo rate and the Consumer Price Index (CPI) is proxied to capture the inflation rate (IF) in the economy. Both variables also serve as instrumental variables in the control of the monetary authority. Finally, the global commodity price (COMM) and global oil price (OP) are the exogenous variables that are included to capture the open economy status of the country. All variables are expressed in natural logarithms except the interest rate and the exchange rates.

\section{The Forecast Variance Decomposition}

Raghavan and Silvapulle (2008) define variance decomposition as a percentage of a shock to a specific variable that is related to either its own innovations or those associated with other dependent variables, at various forecasted time horizons in a model. It analyzes the relative importance of shocks in explaining variations among variables. Therefore, the variance decomposition in this study will help to determine the effects of monetary policy on industrial output growth in South Africa. The monthly variables are allowed to affect each other over a longer period of time. However, we simplified the monthly period into quarterly periods (at 3, 6, 9 and 12 months) for convenient and easy interpretation of the results as shown below:

\subsection{The Variance Decomposition of Industrial Output (IP)}

From the Table 1, the first result explains the proportion of fluctuations to a given variable caused by different shocks to industrial output. In the first quarter in column 2 ( $\log I P)$, the industrial output responds contemporaneously to its own shocks with $92.75 \%$ variation, while other variables explain the remaining $7.25 \%$. Of this $7.25 \%$ variation to industrial output, the inflation rate explains $3.43 \%$; the oil price capturing the external influence explains $2.50 \%$, while the remaining variables do not significantly contribute to the industrial output growth in South Africa. However, after six months (second quarter), the aggregate output (Logag) contributes $9.99 \%$, the inflation rate explains $4.48 \%$ and the oil price explains $3.60 \%$ to the $80.44 \%$ explained by industrial output to its own variation. In addition, the aggregate output, exchange rate, inflation rate, money supply, and oil price appear to be playing an important role in explaining much of the variation in the industrial output growth in the third and fourth quarters, respectively, after a 12-month period. Therefore, the total analysis shows that $\operatorname{LogIP}$ (response to its own variation), $\log I F$ and $\log O P$ significantly respond to variations in industrial output growth for the entire periods $(Q 1-Q 4)$ while $\log C O M M$ and $I N$ were insignificant for the entire periods. LogMS and $E X$ were insignificant in the first and second periods but their variations to $I P$ turned significant in the third 
and fourth quarters, respectively. Also, $\log A G$ responds insignificantly to $I P$ in the first quarter but it responded significantly in the other periods $(Q 2-Q 4)$.

Table 1. Variance decomposition of IP

\begin{tabular}{cccccccccc}
\hline Period & S.E. & $\operatorname{LogIP}$ & LogAG & EX & LogIF & IN & LogMS & $\log C O M M$ & LogOP \\
\hline 3 & 0.01617 & 92.7474 & 0.45558 & 0.46516 & 3.42881 & 0.05952 & 0.19248 & 0.15053 & 2.50045 \\
6 & 0.01805 & 80.4366 & 9.98462 & 0.56124 & 4.47828 & 0.07113 & 0.19860 & 0.67401 & 3.59545 \\
9 & 0.01983 & 69.4833 & 19.8501 & 1.31750 & 3.72541 & 0.24753 & 1.55794 & 0.68595 & 3.13214 \\
12 & 0.02131 & 62.7563 & 23.2390 & 2.04018 & 3.31618 & 0.49512 & 4.81920 & 0.60892 & 2.72504 \\
\hline
\end{tabular}

\subsection{The Variance Decomposition of Aggregate Output (AG)}

Industrial output shows $55.32 \%$ in explaining the variation in aggregate output, while for aggregate output, its own shocks shows $41.65 \%$ in the first quarter. The inflation rate only shows $1.20 \%$ as other variables do not contribute significantly to the variation in aggregate output. However, money supply and interest rates contribute significantly with $3.05 \%$ and $2.09 \%$ in the second quarter. Also, in the third quarter, industrial output contributes $27.60 \%$. The aggregate output contributes $59.18 \%$ to its own lagged value (variation), the exchange rate contributes $1.19 \%$, interest rate contributes $2.83 \%$ and money supply contributes $7.49 \%$, totaling $98.29 \%$, while other variables remain insignificant to the variations in aggregate output. However, in the fourth quarter, money supply shows $13.64 \%$, the interest rate shows a $3.40 \%$ variation, exchange rate shows $3.28 \%$, the industrial output shows $19.80 \%$ to the significant variation in aggregate output, and the aggregate output shows $58.35 \%$ to its own variation. Consequently, the total analyses of each variable response to aggregate output shows that LogIP significantly contributes to the variation in aggregate output for all quarters while $\operatorname{LogOP}$ and $\log C O M M$ are insignificant. $\log M S$ and $I N$ can be summed to show $75 \%$ (Q2-Q4) variations in explaining aggregate output while $E X$ shows $50 \%(\mathrm{Q} 3-\mathrm{Q} 4)$ variations and LogIF shows $25 \%$ (only in Q1).

Table 2. Variance decomposition of AG

\begin{tabular}{cccccccccc}
\hline Period & S.E. & LogIP & LogAG & EX & LogIF & IN & LogMS & LogCOMM & LogOP \\
\hline 3 & 0.00620 & 55.3178 & 41.6485 & 0.47651 & 1.19655 & 0.82465 & 0.14525 & 0.10881 & 0.28193 \\
6 & 0.00866 & 35.6184 & 57.1509 & 0.63971 & 0.83452 & 2.08741 & 3.05377 & 0.21764 & 0.39765 \\
9 & 0.01104 & 27.6004 & 59.1747 & 1.18598 & 0.82142 & 2.83294 & 7.48554 & 0.36012 & 0.53896 \\
12 & 0.01321 & 19.7960 & 58.3518 & 3.27945 & 0.58628 & 3.40139 & 13.6364 & 0.41382 & 0.53493 \\
\hline
\end{tabular}

\section{The SVAR Forecasting of Variables}

The time series data used in a model is forecasted to determine the predictive power and accuracy of the structural VAR in an econometrics model. Following the graphical approach of Harvey (1989) and Batten and Thornton (1983), the out-of-sample forecasting is employed to show the different trend types that include seasonal components, trend components and irregular components. In the forecasting process, this study is largely based on the view of Diebold and $\mathrm{Li},(2006, \mathrm{p}$. 253) to develop a regression model using time series data from 1994:01-2010:12 to estimate the model and sample data from 2011:01-2013:12 for the ex-post (all data have been identified) static and dynamic forecasting. The "root mean-squared error" serves as the benchmark for the evaluation of the forecasting value and the actual value (see Harvey, 1989; Clarida et al., 2003). The lower the root mean-squared error (value), the smaller the error margin line (gap between the actual value and the forecasted value), hence the more satisfactory the predictive power of the model. In contrast, the greater or the bigger the value of the root mean-squared error, the wider the gap between the actual value and the forecasted value and the lesser the satisfactory power of the model. The forecasting process further presented a line graph (figure) obtained with the use of the Eviews software and by a scientific method of Pair-wise correlation coefficient matrix (pwcorr) using STATA software. This method assists the study in verifying the true movement and correlation existence between the actual variable (value) and the forecasted variable in order to substantiate and confirm the predictive power of the model for policy recommendation. The detailed results obtained from the pwcorr are shown in Appendix 2 and Appendix 3, respectively.

\section{Static versus Dynamic Forecasting}

In this study, combined forecasting is carried out to distinguish between the static and dynamic approaches using 
the root mean-squared error as the benchmark. The combined forecasting technique was first introduced by Bates and Granger in 1969 and has since been applied by many researchers with the belief that it can improve predictive accuracy (see Clemen, 1989; Armstrong, 1989).

In general, static forecasting (simulation modelling) is based on current exposures and assumes a constant balance with no new growth. It uses actual rather than forecasted values (it can only be used when actual data are available). Conversely, dynamic forecasting relies on detailed assumptions regarding changes (increases or decreases) within the economy. It uses the previously forecasted values of the lagged variable. According to Menezes et al. (2000), reviewing both methods will lead to distinct preferences. In addition, Hibon and Evgeniou (2005) argue that the advantage of combined forecasts is not that the best possible combinations perform better than the possible individual forecasts, but that it is less risky, in practice, to combine forecasts than to select individual forecasting methods. The analysis of static and dynamic forecasting in this study will offer researchers the opportunity to choose from the two forecasting methods and select the most accurate or predictive approach that would provide useful information about future events.

\subsection{The Static and Dynamic Forecasting of Industrial Sector Performance (IP)}

The data estimates for industrial sector performance as an endogenous variable in the regression model ranges from 1994:01 to 2010:12. Figures 1a and 1c show the out-of-sample forecasting error for static and dynamic forecasting. In Figure 1a, the forecasting horizon is from 2011:01-2013:12 as the two red lines show a 95\% confidence interval between the two $( \pm 2)$ standard deviation error lines. The movement of logipf within the confidence interval shows that the forecasting model is satisfactory as this is further confirmed by the lower value of 0.011209 as the root-mean squared error. Figure $1 \mathrm{~b}$ illustrates the line figure to show the movement of logip and logipf for the static forecasting.

There was a co-movement in the actual and the forecasted values of industrial output (IP) for the forecast period. This is further confirmed by the pwcorr. It shows a strong positive correlation of about $94 \%$ between the actual and the forecasted value of the industrial sector's performance. Furthermore, the dynamic forecasting figures also have a lower root mean-squared error of 0.029469 and satisfactory predictive power as shown in Figure 1c and confirmed by the line Figure 1d for the co-movements of the actual and forecasted value of the industrial sector performance (output). The pwcorr equally shows that a strong positive relationship (75\%) exists between logip and logipf.

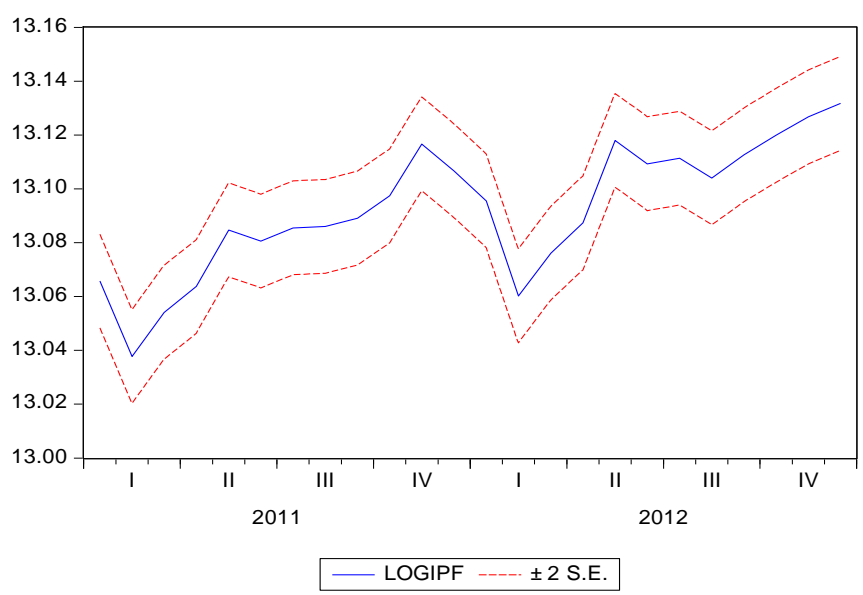

\begin{tabular}{|c|c|}
\hline \multicolumn{2}{|l|}{ Forecast: LOGIPF } \\
\hline \multicolumn{2}{|l|}{ Actual: LOGIP } \\
\hline \multicolumn{2}{|c|}{$\begin{array}{l}\text { Forecast sample: } 2011 \mathrm{M} 012012 \mathrm{M} 12 \\
\text { Included observations: } 24\end{array}$} \\
\hline Root Mean Squared Error & 0.011209 \\
\hline Mean Absolute Error & 0.008173 \\
\hline Mean Abs. Percent Error & 0.062492 \\
\hline Theil Inequality Coefficient & 0.000428 \\
\hline Bias Proportion & 0.301390 \\
\hline Variance Proportion & 0.085656 \\
\hline Covariance Proportion & 0.612954 \\
\hline
\end{tabular}

Figure 1a. Static forecasting for LogIP 


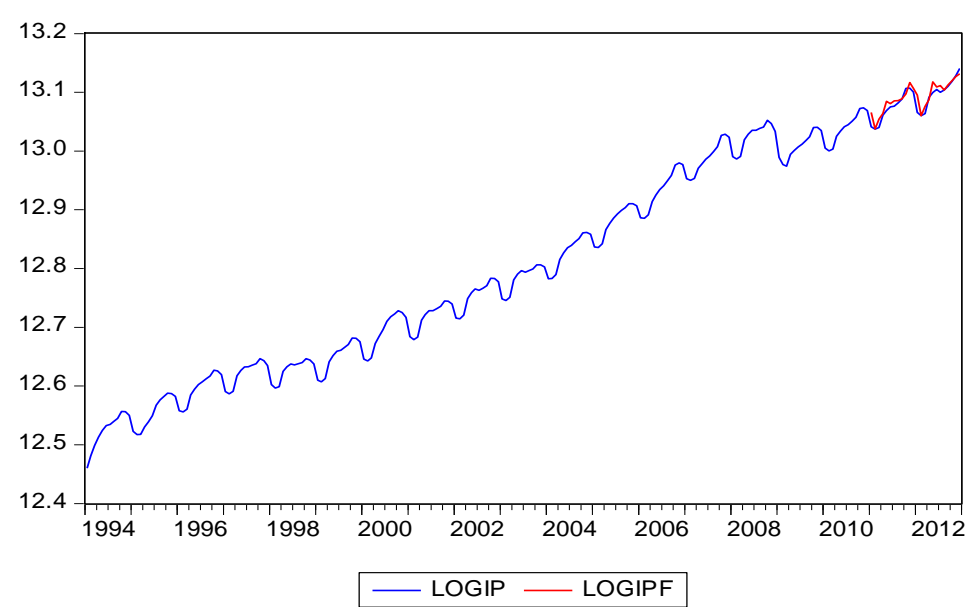

Figure 1b. Static line for $\log I \mathrm{P}$
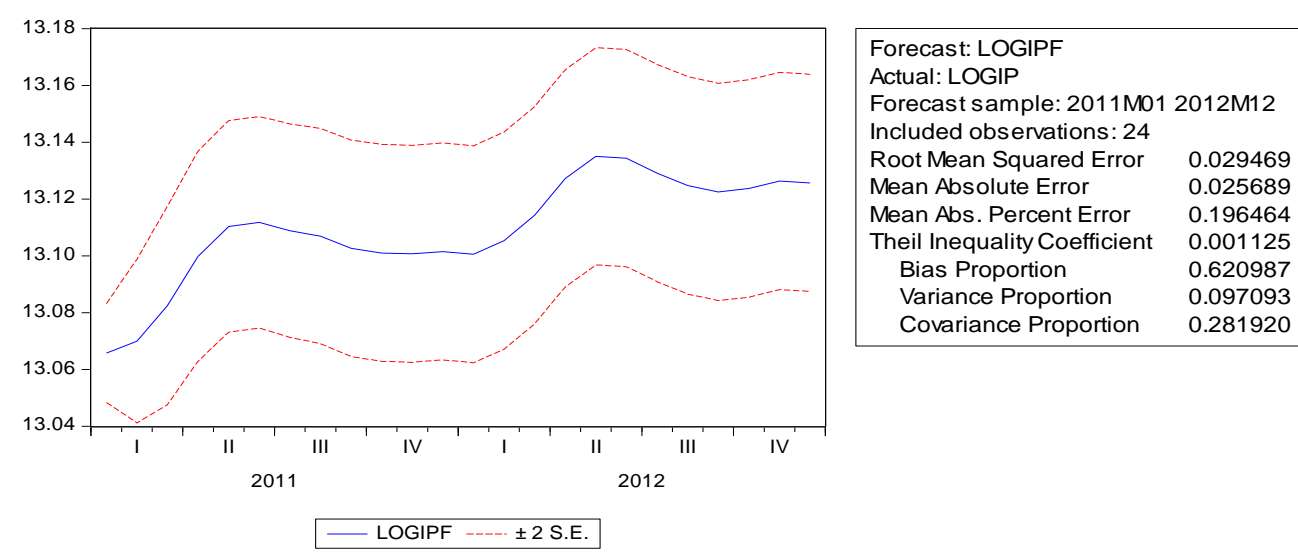

Figure 1c. Dynamic forecasting for LogIP

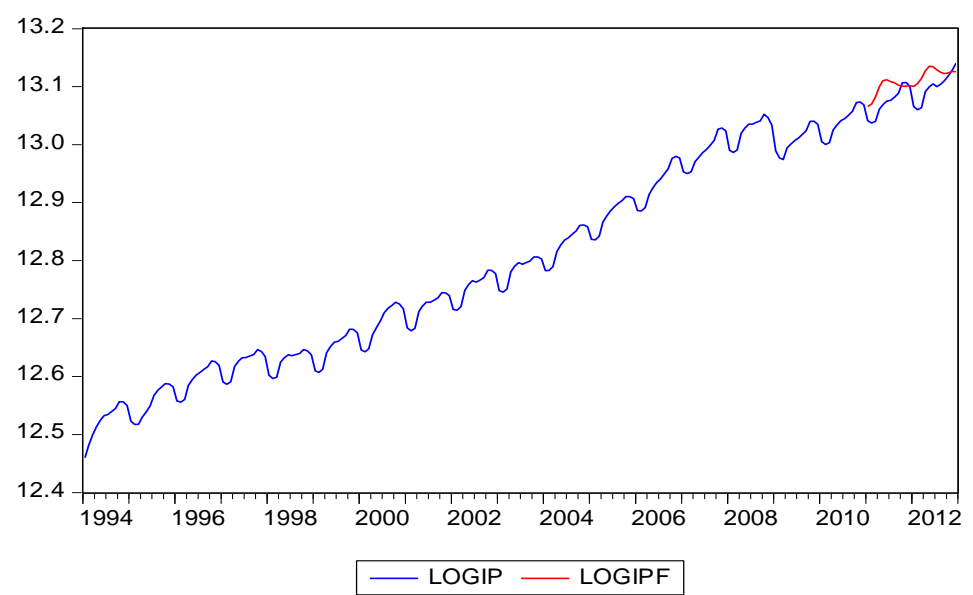

Figure 1d. Dynamic line for LogIP

\subsection{The Static and Dynamic Forecasting of Aggregate Output (AG)}

According to Figure 2a, the actual value of aggregate output and the forecasted value obtained from the static forecasting drifts together within the $95 \%$ confident interval. This equally shows the predictive and satisfactory power of the model, which is confirmed by the smaller value of the root-mean squared error of 0.003661 . The movement is further substantiated in Figure $2 \mathrm{~b}$ using the line and symbol figure. The logag and logagf move together throughout the forecasting horizon and thus further confirms the satisfactory and predictive ability of the 
model utilized with a very strong positive correlation of $97 \%$ as indicated by the pwcorr.

On the other hand, the dynamic forecast has a root mean-squared error of 0.020323 , which also indicates a satisfactory and predictive power for the model. Figures $2 \mathrm{c}$ and $2 \mathrm{~d}$ show the movements of the actual and forecasted values of aggregate output and this has a strong positive correlation of $83 \%$ as shown by pwcorr.

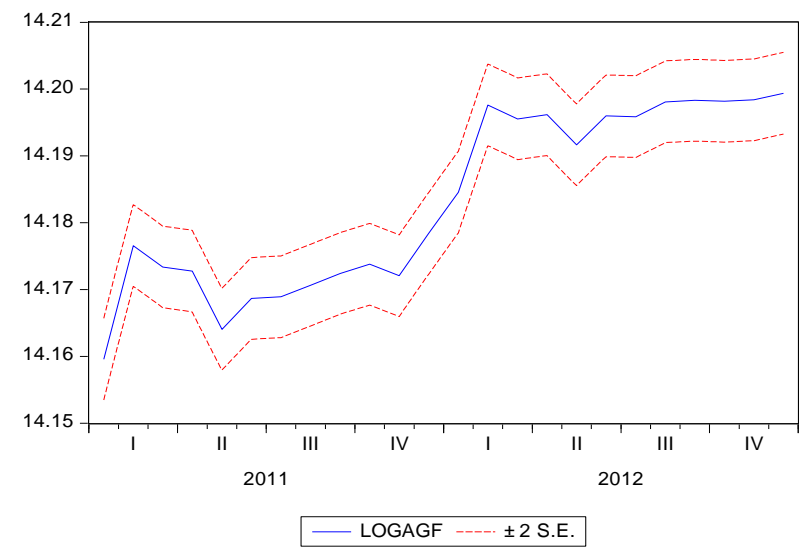

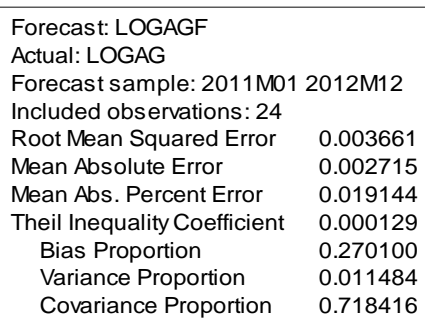

Figure 2a. Static forecasting for $\log A G$

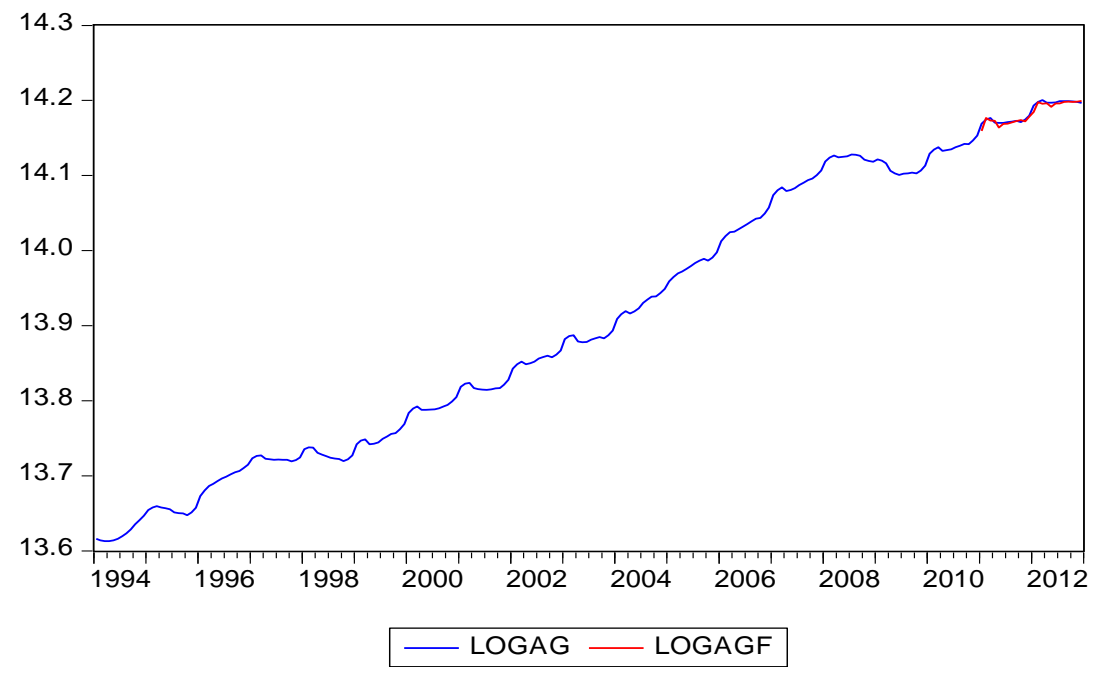

Figure 2b. Static line for $\log A G$

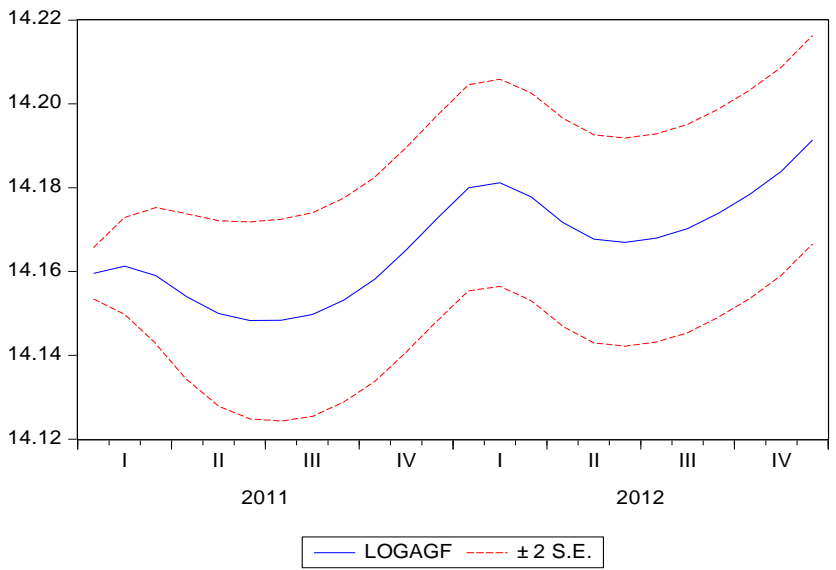

Forecast: LOGAGF

Actual: LOGAG

Forecast sample: 2011M01 2012M12

Included observations: 24

Root Mean Squared Error 0.020323

Mean Absolute Error $\quad 0.019001$

Mean Abs. Percent Error $\quad 0.133934$

Theil Inequality Coefficient 0.000717

Bias Proportion $\quad 0.874129$

Variance Proportion

Covariance Proportion $\quad 0.124437$

Figure 2c. Dynamic forecasting for $\log A G$ 


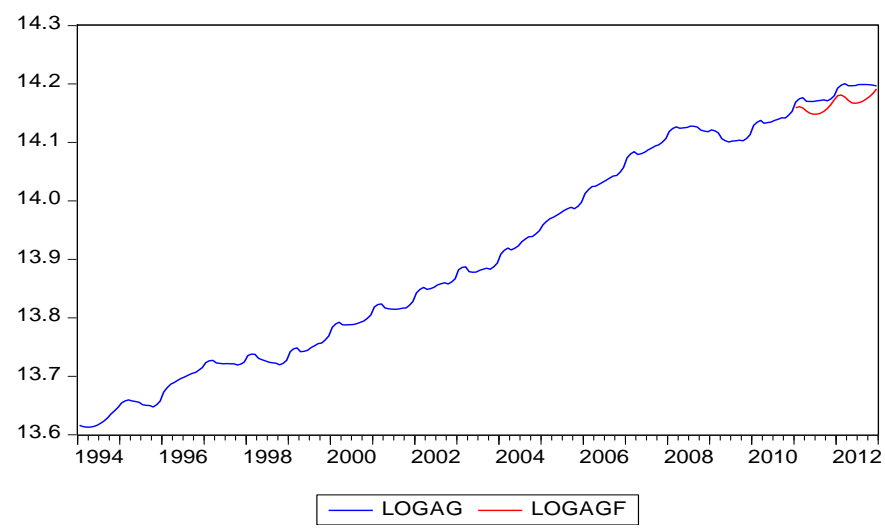

Figure 2d. Dynamic line for LogAG

\subsection{The Static and Dynamic Forecasting of the Exchange Rate (EX)}

The exchange rate as a policy variable also gives a good result. The predictive ability of the model is quite satisfactory with a root-mean squared error of 0.245802 . Although, the value of the root-square mean is a bit higher and far from zero due to instability in the external value of the exchange rate system in the global market and the current depreciation of the external value of the Rand exchange rate. The predictive ability of the model used in this study was still satisfactory and can account for both variations in the domestic and external value of the currency (exchange rate system) as shown in Figure 3a. The satisfactory predictive power of the model is further confirmed in Figure $3 b$. The exchange rate and exchange rate forecast (ex and exf) move together in the same direction and the pwcorr shows a 94\% positive correlation between the actual value of the exchange rate and the forecasted value. However, the dynamic forecasting brought out the likely changes (increase or decrease) in the economy. The root mean-squared error was very high and far from zero (1.901262) as shown in Figure 3c. This is further confirmed in Figure 3d. The pwcorr shows a strong negative correlation of $87 \%$ between ex and exf .

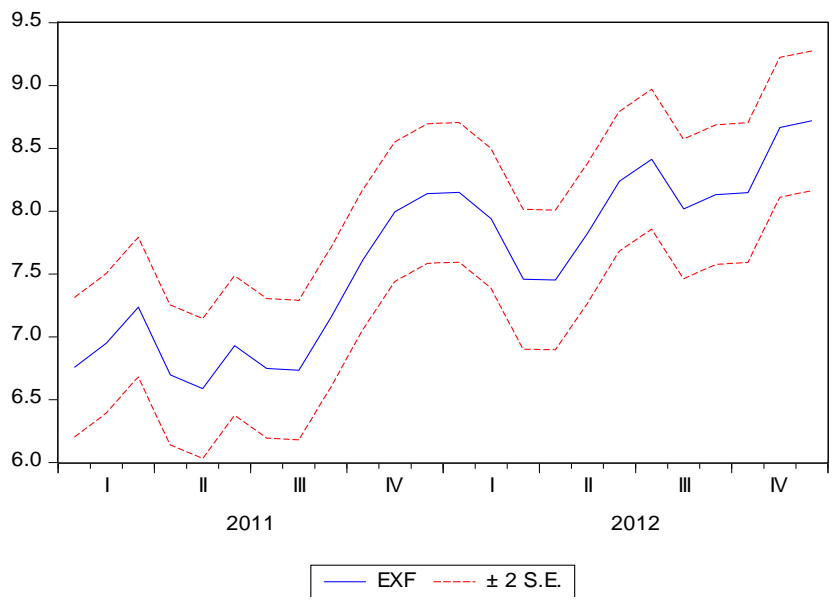

Forecast: EXF

Actual: EX

Forecast sample: 2011M01 2012M12

Included observations: 24

Root Mean Squared Error 0.245802

Mean Absolute Error $\quad 0.214469$

Mean Abs. Percent Error 2.782280

Theil Inequality Coefficient 0.015961

Bias Proportion $\quad 0.236504$

Variance Proportion $\quad 0.000096$

Covariance Proportion 0.763399

Figure 3a. Static forecasting for EX 


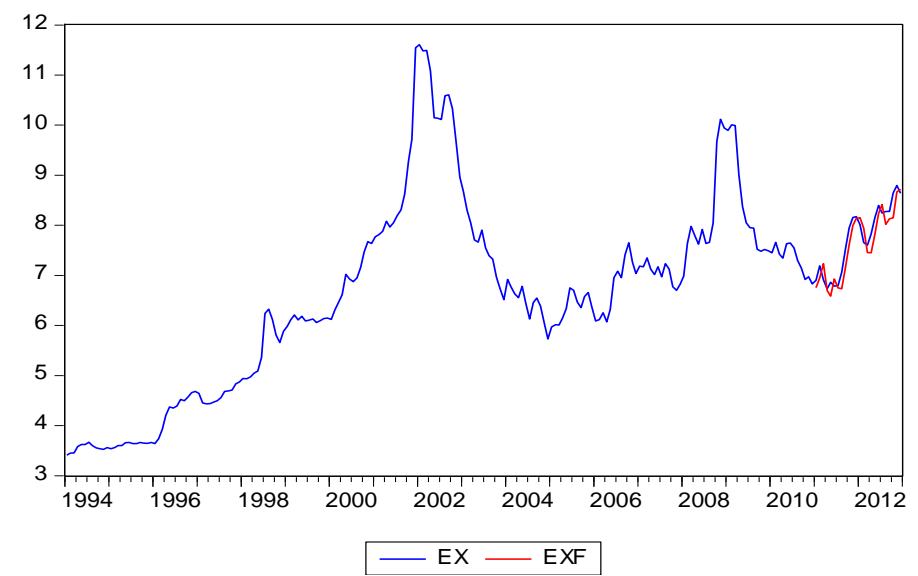

Figure 3b. Static line for EX

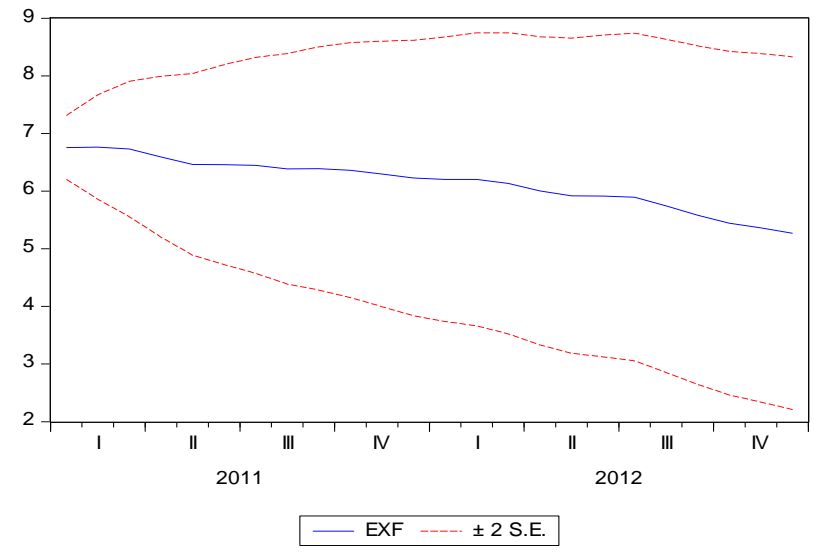

\section{Forecast: EXF} Actual: EX

Forecast sample: 2011M01 2012M12 Included observations: 24

Root Mean Squared Error 1.901262

Mean Absolute Error $\quad 1.583852$

Mean Abs. Percent Error 19.47782

Theil Inequality Coefficient 0.136565

Bias Proportion $\quad 0.693977$

Variance Proportion $\quad 0.015369$

Covariance Proportion $\quad 0.290654$

Figure 3c. Dynamic forecasting for EX

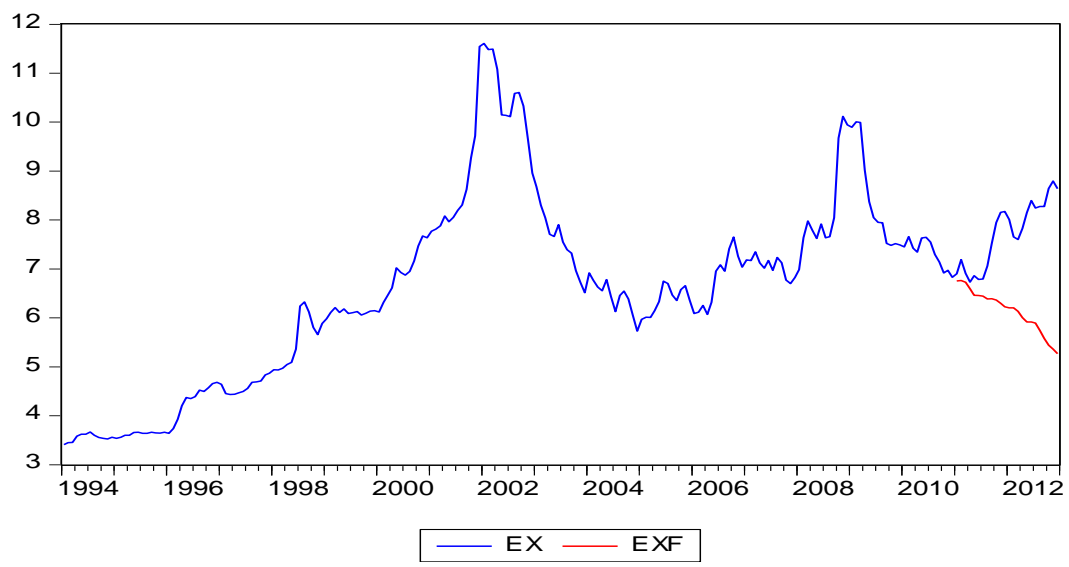

Figure 3d. Dynamic line for EX

\subsection{The Static and Dynamic Forecasting of the Inflation Rate (IF)}

The CPI is the proxy to capture the actual value of the logif for data estimates in the SVAR model. Figure 4a shows the movement of the logiff along the $95 \%$ confidence interval. There is a close movement between the logif and $\operatorname{logiff}$, which indicates that there is a satisfactory forecasting ability of the model as confirmed by the lower value of the root-mean squared error of 0.004549 . In addition, Figure $4 \mathrm{~b}$ shows a clear picture to re-affirm 
the predictive ability of the model and to confirm the strong positive correlation of $99 \%$. This shows that the actual value of the inflation rate and the forecasted value move closely together. The dynamic forecasting has its root mean-squared error of 0.042398 as shown in Figure 4c. The line Figure 4d shows the co-movements between logif and logiff with $97 \%$ strong Pair-wise correlation coefficients ( $p w c o r r$ ).

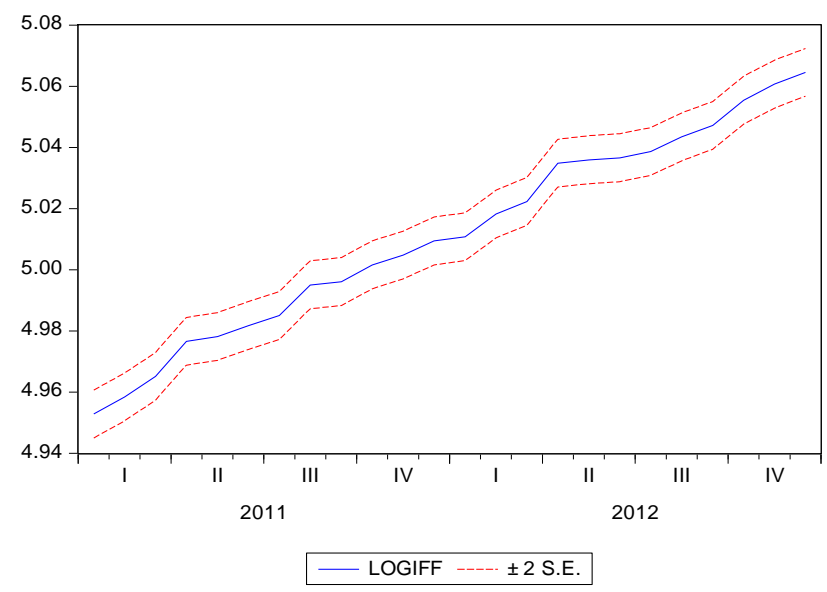

\section{Forecast: LOGIFF}

Actual: LOGIF

Forecast sample: 2011M01 2012M12

Included observations: 24

Root Mean Squared Error 0.004549

Mean Absolute Error

Mean Abs. Percent Error 0.072878

Theil Inequality Coefficient 0.000454

Bias Proportion $\quad 0.644558$

Variance Proportion $\quad 0.008668$

Covariance Proportion $\quad 0.346774$

Figure 4a. Static frecasting for $\operatorname{LogIF}$

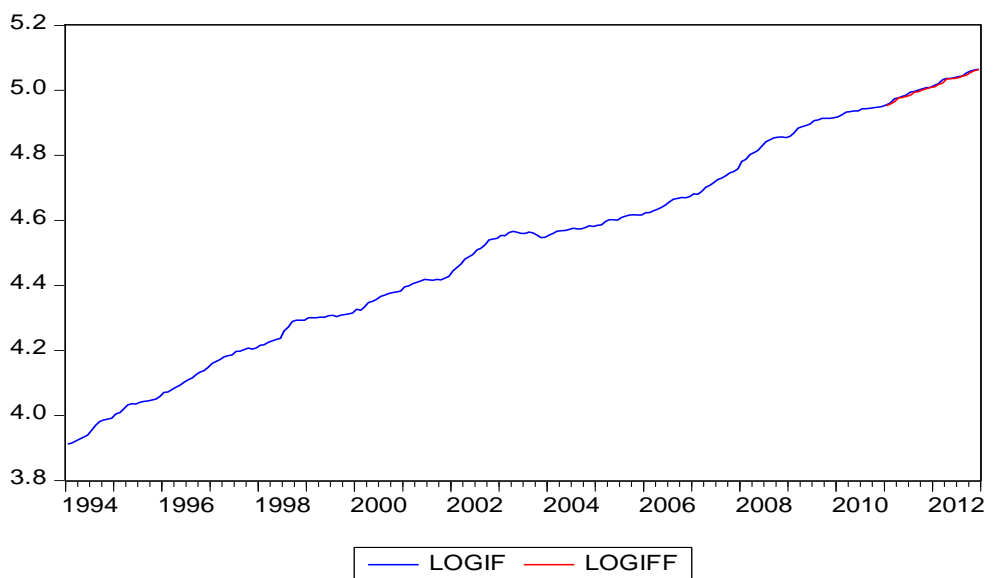

Figure 4b. Static line for LogIF

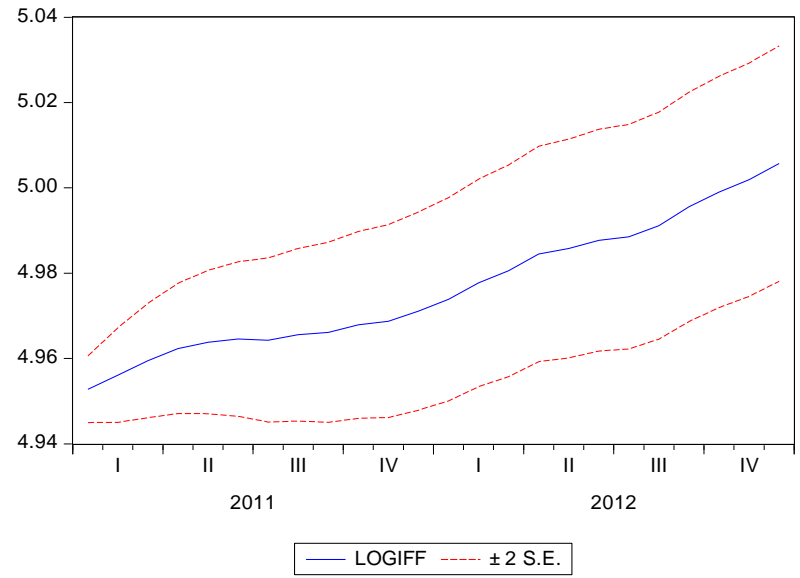

Forecast: LOGIFF

Actual: LOGIF

Forecast sample: 2011M01 2012M12

Included observations: 24

Root Mean Squared Error 0.042398

Mean Absolute Error $\quad 0.038581$

Mean Abs. Percent Error 0.767139

Theil Inequality Coefficient 0.004243

Bias Proportion $\quad 0.828048$

Variance Proportion $\quad 0.161032$

Covariance Proportion $\quad 0.010920$

Figure 4c. Dynamic forecasting for LogIF 


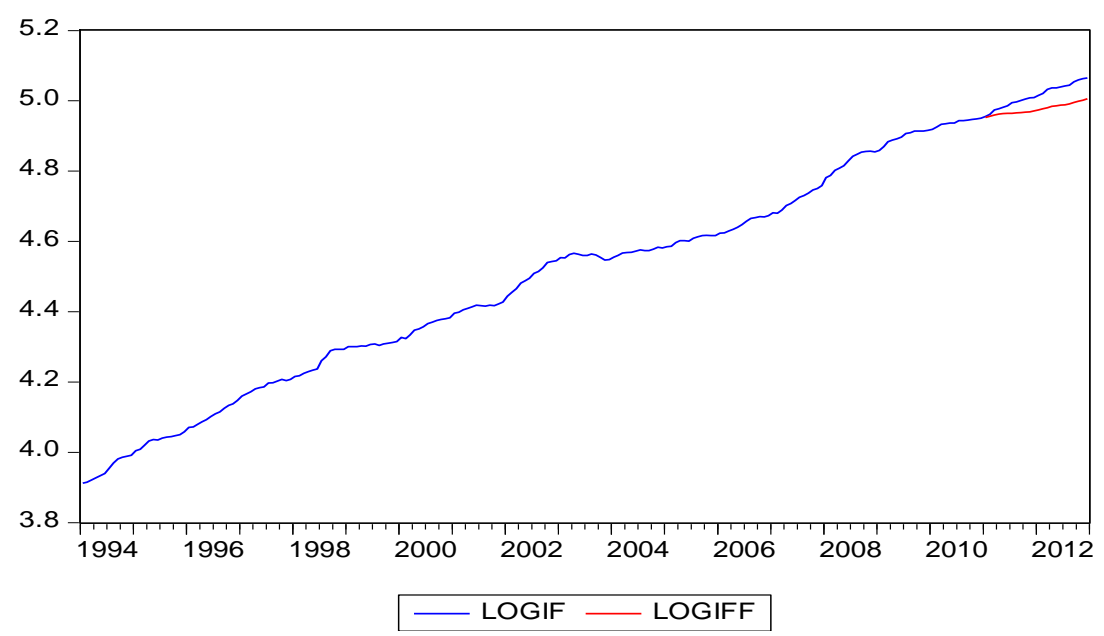

Figure 4d. Dynamic line for LogIF

\subsection{The Static and Dynamic Forecasting of the Interest Rate (IN)}

The frequent changes in the interest rate as a policy variable to control inflation in the economy give the root mean-squared a high value. The out-of-sample static forecasting model is nonetheless satisfactory in determining the movement of the actual and the forecasted values of the interest rate in the economy for the forecast horizon. IN and INF move together within the two standard deviation error lines as confirmed by the value of the root-mean squared error of 0.155570 as shown in Figure 5a. This means that the predictive ability of the model for the actual value and the forecasted value for the interest rate is satisfactory and can guarantee that the future rate can be set by the Reserve Bank within the economy. Figure 5b shows the co-movements of the variables and further confirms the ability of the model to predict the interest rate in the economy with a strong (pwcorr) positive correlation of $83 \%$. However, the dynamic forecasting has a high root mean-squared error of 1.168728 as shown in Figure $5 \mathrm{c}$ and is thus capable of identifying the likely changes in the interest rate. Figure $5 \mathrm{~d}$ shows the movement of in and inf. The pwcorr shows a strong positive relationship of $84 \%$ between the actual value and the forecasted value of the interest rate in the economy.

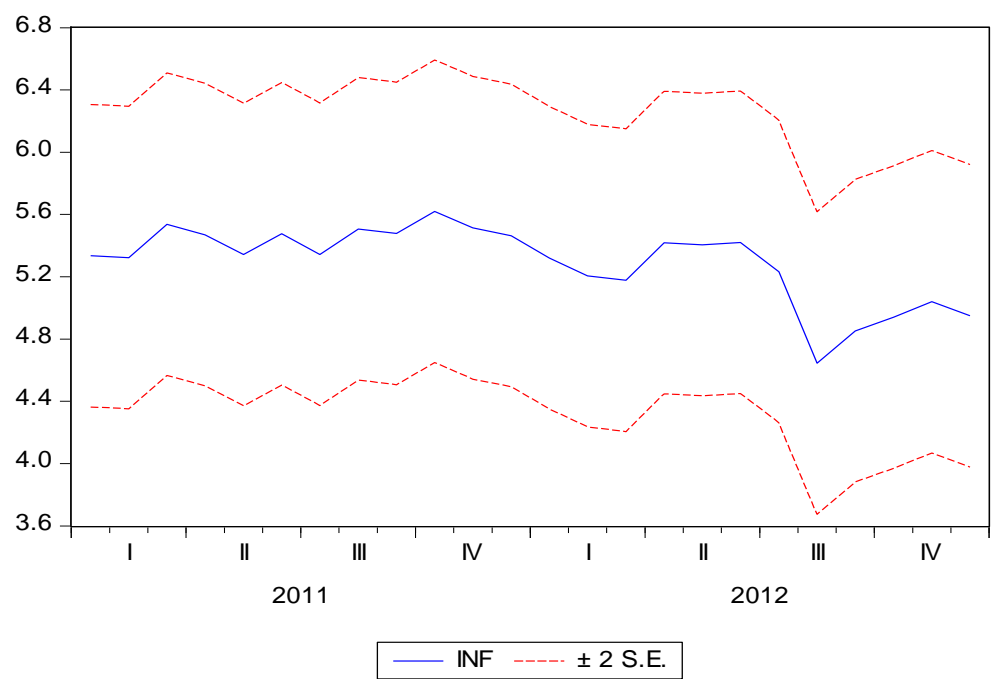

Forecast: INF

Actual: IN

Forecast sample: 2011M01 2012M12

Included observations: 24

Root Mean Squared Error $\quad 0.155570$

Mean Absolute Error

0.120066

Mean Abs. Percent Error 2.249934

Theil Inequality Coefficient 0.014570

Bias Proportion $\quad 0.281845$

Variance Proportion $\quad 0.023541$

Covariance Proportion $\quad 0.694613$

Figure 5a. Static forecasting for IN 


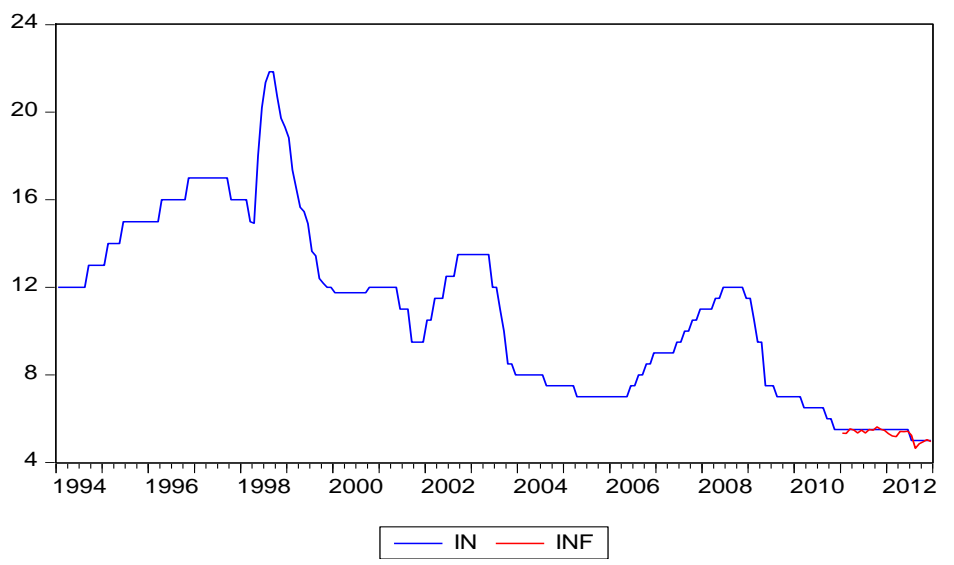

Figure $5 b$. Static line for IN
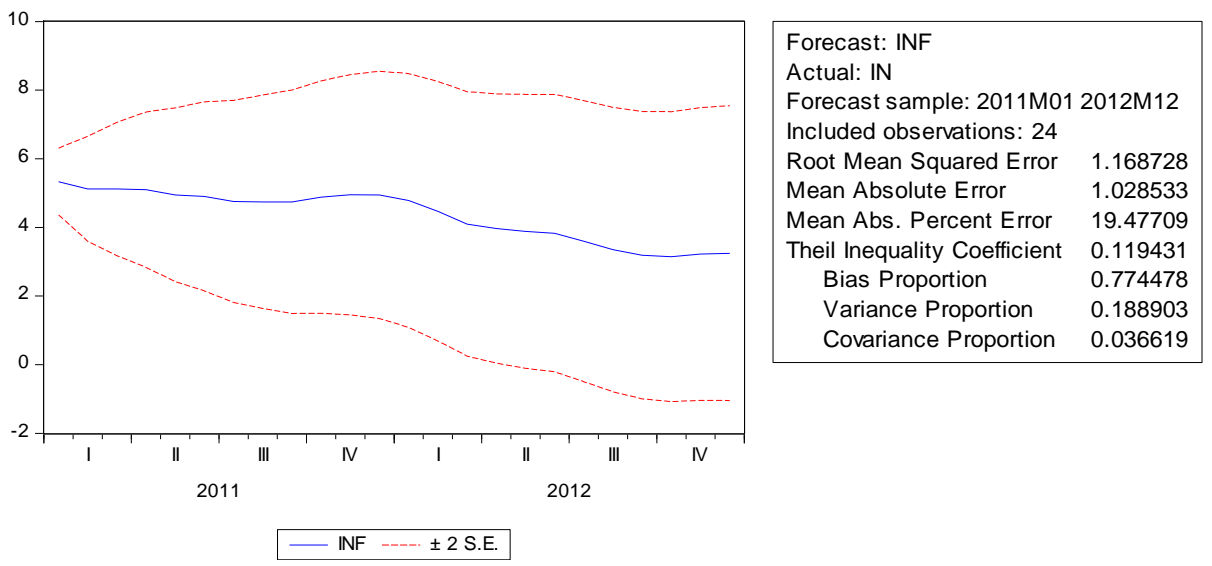

Figure 5c. Dynamic forecasting for IN

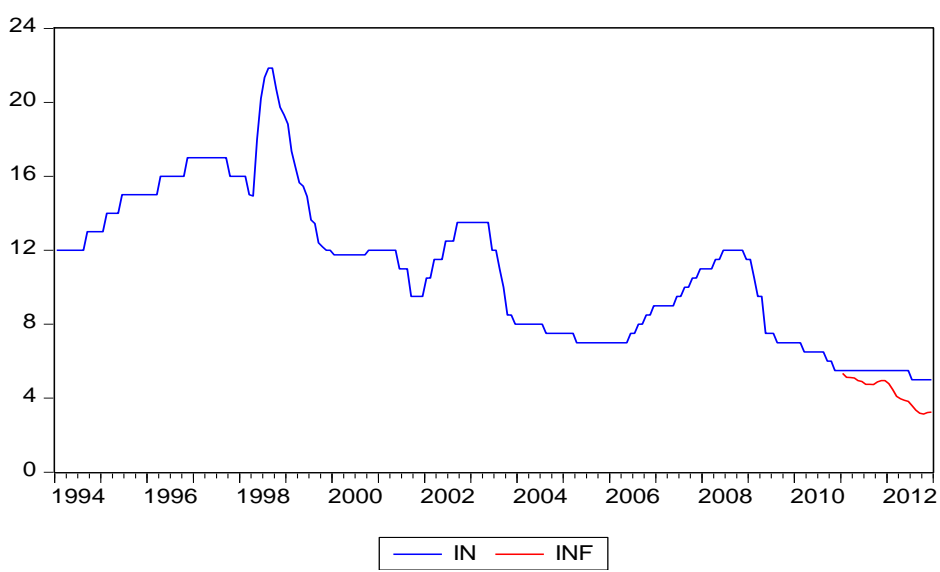

Figure 5d. Dynamic line for IN

\subsection{The Static and Dynamic Forecasting of Money Supply (MS)}

The forecasting power of money supply in the model is satisfactory as the actual value and predicted values move closely together. As illustrated in Figure 6a, the logms and logms $f$ move very close to each other along the two standard deviation error lines and this is further established by the small value of the root-mean squared error of 0.018489. Figure 6b shows the movements of logms and logms $f$ for the entire forecasting period with a $95 \%$ 
strong positive relationship. On the other hand, the dynamic forecasting has a root mean-squared error of 0.093869 as shown in Figure $6 \mathrm{c}$, hence the good predictive ability of the model. The line figure $6 \mathrm{~d}$ shows the movements of the variables (logms and $\log m s f$ ). In addition, the pwcorr shows a strong positive correlation of $95 \%$ between the actual and forecasted value of money supplies.
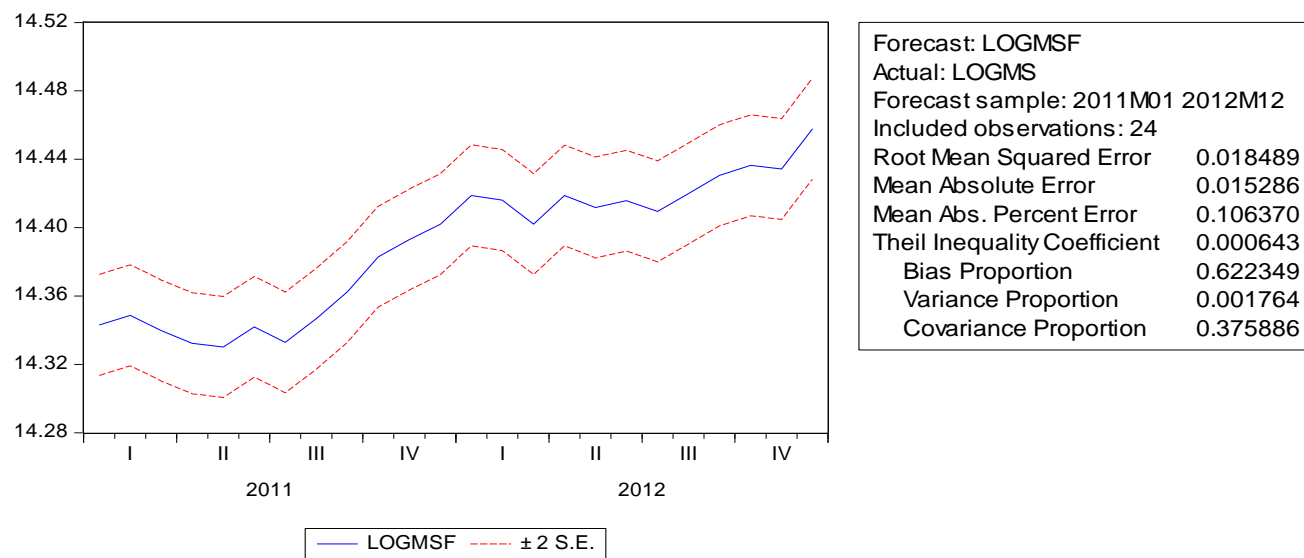

Figure 6a. Static forecasting for $\log M S$

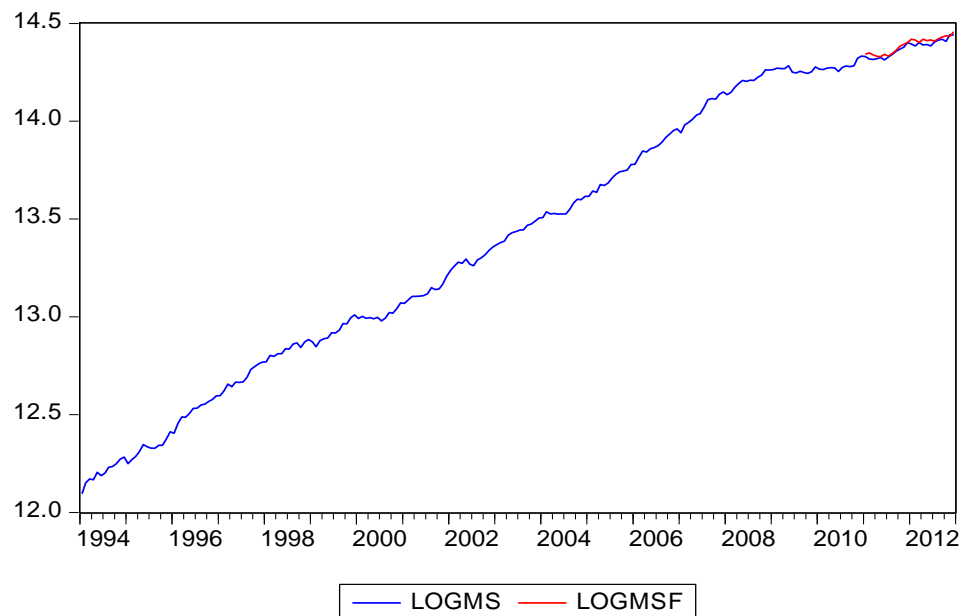

Figure 6b. Static line for LogMS

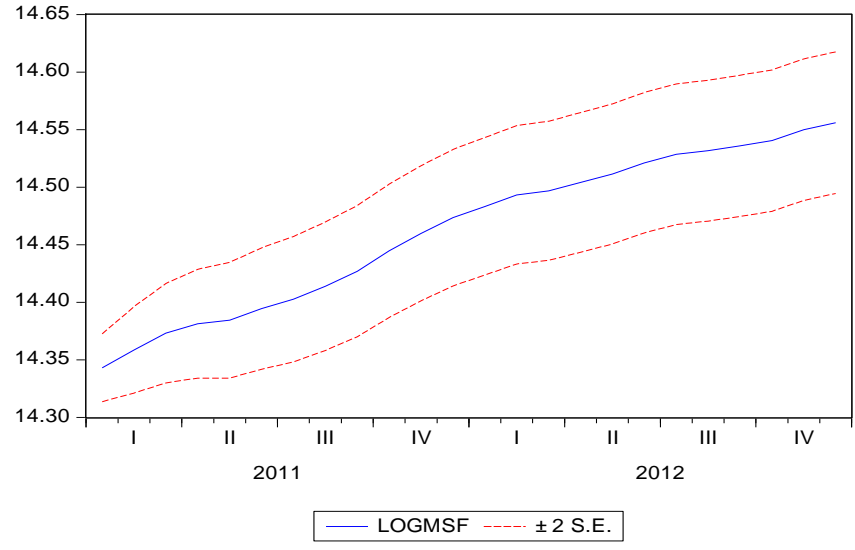

Forecast: LOGMSF

Actual: LOGMS

Forecast sample: 2011M01 2012M12

Included observations: 24

Root Mean Squared Error $\quad 0.093869$

Mean Absolute Error $\quad 0.088788$

Mean Abs. Percent Error $\quad 0.617255$

Theil Inequality Coefficient $\quad 0.003255$

Bias Proportion $\quad 0.894672$

Variance Proportion $\quad 0.077700$

Covariance Proportion $\quad 0.027628$

Figure 6c. Dynamic forecasting for LogMS 


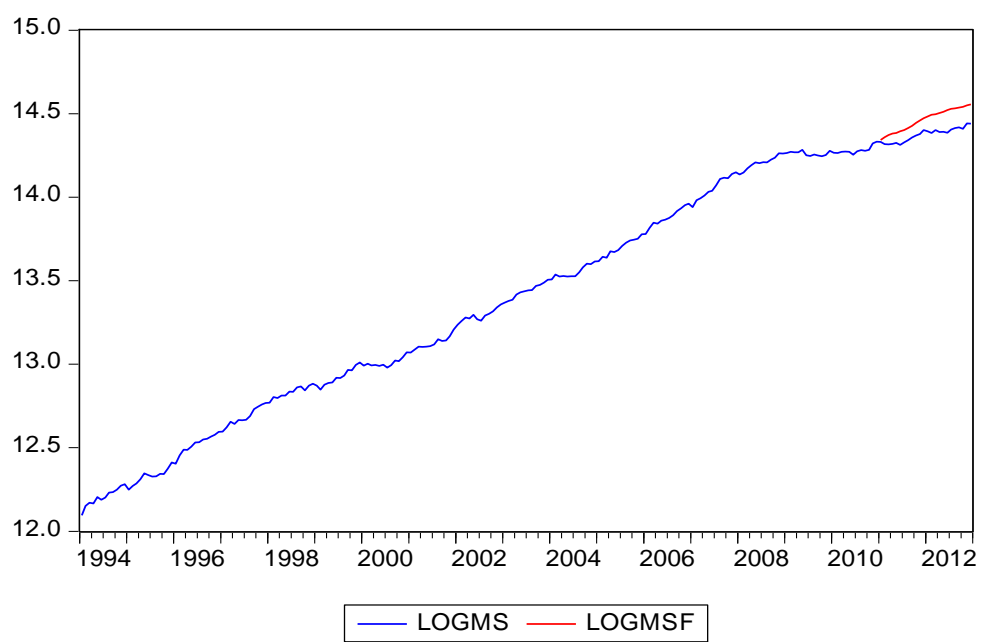

Figure 6d. Dynamic line for LogMS

\subsection{The Static and Dynamic Forecasting of Commodity Prices (COMM)}

This is the commodity price captured by South Africa's main exports and it represents an external variable that is shock responsive and that has an impact on the domestic variables. Based on the results obtained in Figure 7a, the $\log \mathrm{comm} f$ moves very closely within the two standard deviation error lines with a lower root mean-squared error of 0.010966 , while Figure $7 \mathrm{~b}$ shows the co-movements of the logcomm and logcomm $f$ for the whole static forecasting horizon. The benchmark for the forecasting confirms the satisfactory power of the model to predict future commodity prices. The pwcorr also confirms a strong correlation of $92 \%$ between the actual value of commodity prices and the forecasted value. Furthermore, the dynamic forecasting has a root mean-squared error of 0.039149 as indicated in Figure 7c and the co-movements of logcomm and logcommf are shown in Figure 7d. The movements also show the satisfactory power of the model with pwcorr coefficients of 51\%.

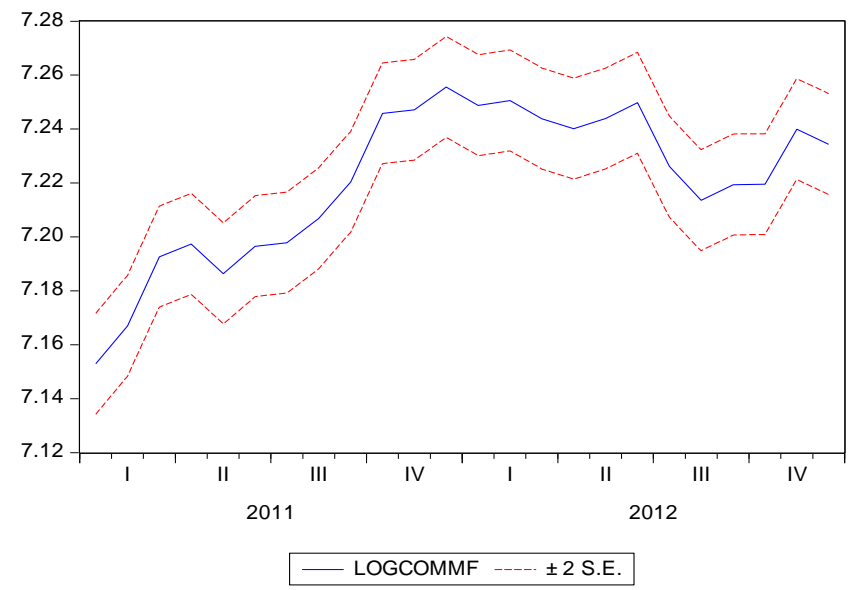

Forecast: LOGCOMMF Actual: LOGCOMM

Forecast sample: 2011M01 2012M12

Included observations: 24

Root Mean Squared Error 0.010966

Mean Absolute Error $\quad 0.008673$

Mean Abs. Percent Error 0.120126

Theil Inequality Coefficient 0.000759

Bias Proportion $\quad 0.012086$

Variance Proportion $\quad 0.082303$

Covariance Proportion 0.905611

Figure 7a. Static forecasting for LogCOMM 


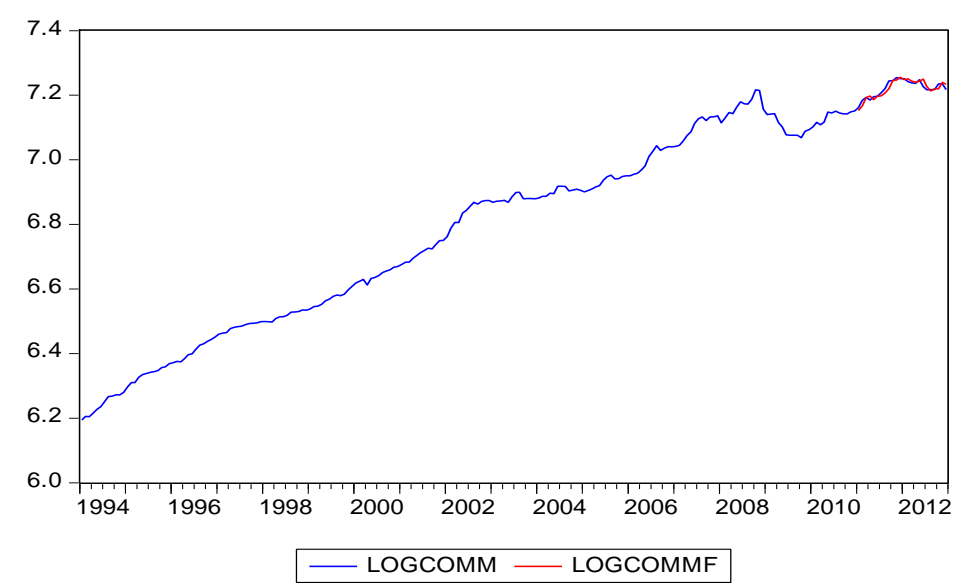

Figure 7b. Static line for LogCOMM

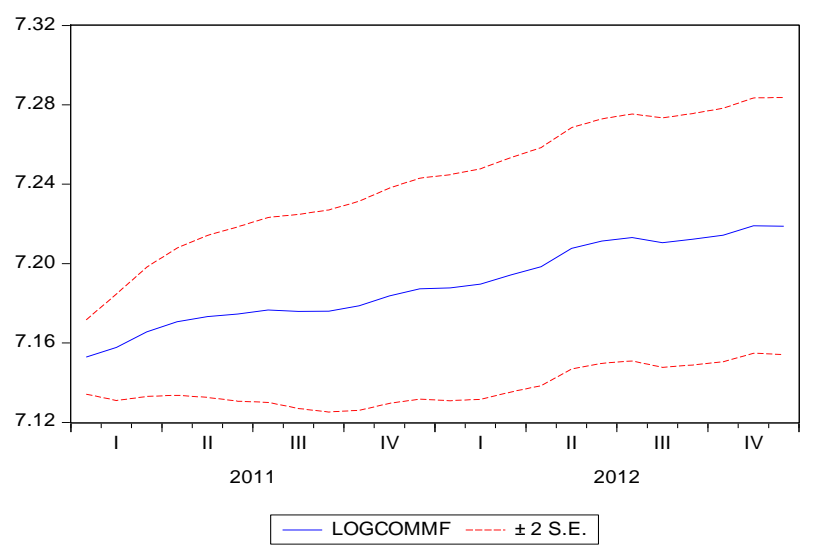

Forecast: LOGCOMMF

Actual: LOGCOMM

Forecast sample: 2011M01 2012M12

Included observations: 24

Root Mean Squared Error 0.039149

Mean Absolute Error $\quad 0.032380$

Mean Abs. Percent Error 0.447681

Theil Inequality Coefficient 0.002716

Bias Proportion $\quad 0.680143$

Variance Proportion $\quad 0.016150$

Covariance Proportion $\quad 0.303707$

Figure 7c. Dynamic forecasting for LogCOMM

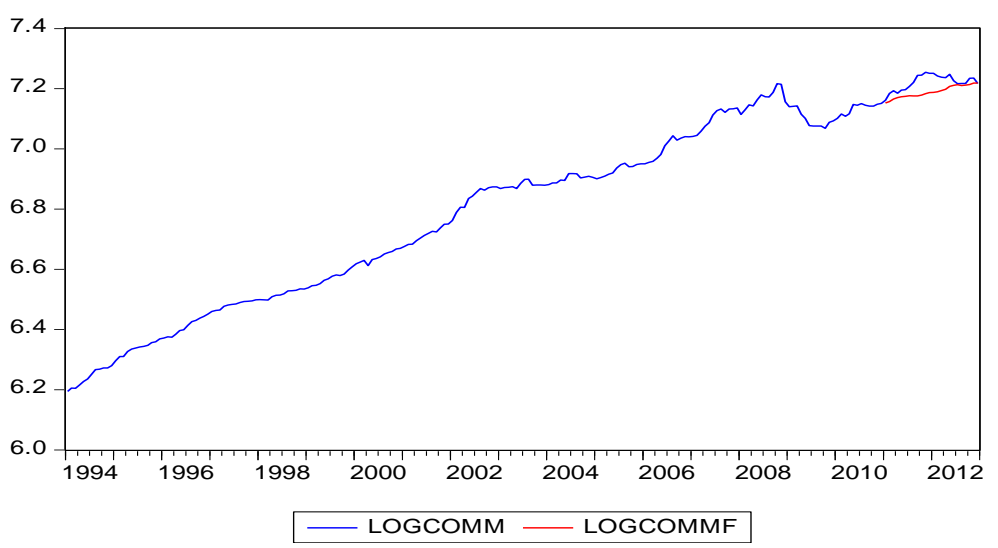

Figure 7d. Dynamic line for LogCOMM

\subsection{The Static and Dynamic Forecasting of Oil Prices (LogOP)}

The oil price also captures the external shock from the global market that persistently affects domestic prices due to its spillover effects. An increase in the price of oil also leads to an increase in domestic prices. In the results presented, by estimating the model the figures show up-spring and down-spring movements of the actual and forecasted values. In Figure 8a, the logopf moves within the two standard deviation error lines within the 95\% confidence interval. The low root mean-squared error of 0.052861 shows the predictive power of the model to be satisfactory. Furthermore, Figure 8b shows that logcomm and logcommf are moving closely together for the forecasting periods with a strong positive correlation of $69 \%$. Moreover, the dynamic forecasting has a root 
mean-squared error of 0.098685 as shown in Figure $8 \mathrm{c}$ and by the covariance of the variables in Figure $8 \mathrm{~d}$, the actual value of the oil price and the forecasted value drifts together. However, the pwcorr shows a weak negative relationship of -0.1243 between logop and logopf. This conforms to the literature, that dynamic forecasting facilitates the generation of changes (increases or decreases) within the economy and provides small forecasting improvements compared to static forecasting (see details in Schumacher \& Breitung, 2008).

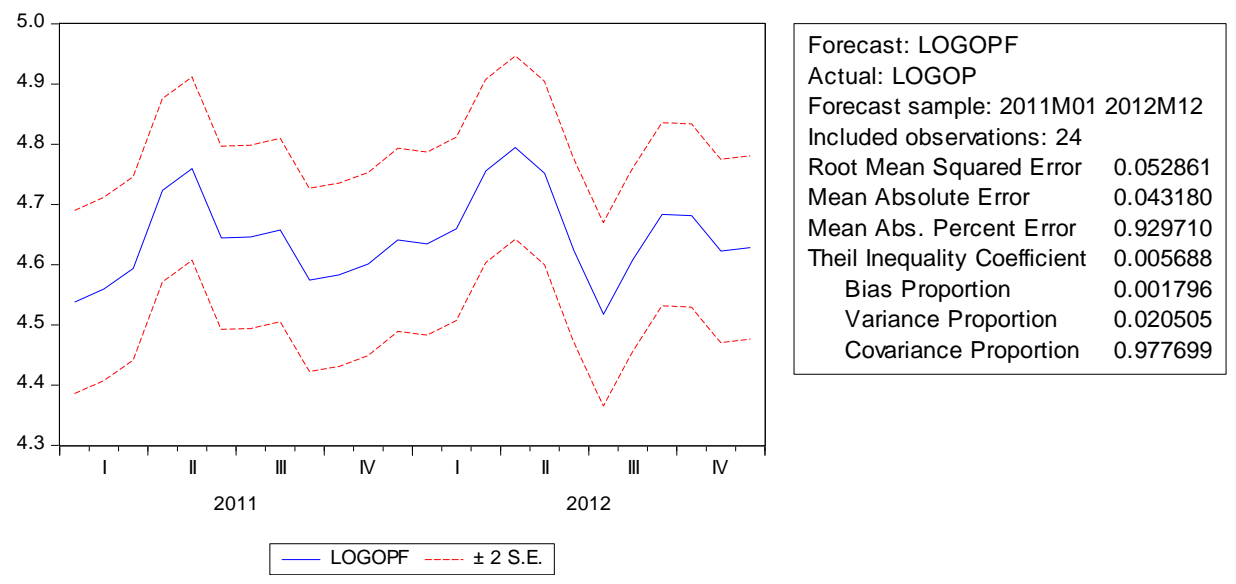

Figure 8a. Static forecasting for LogOP

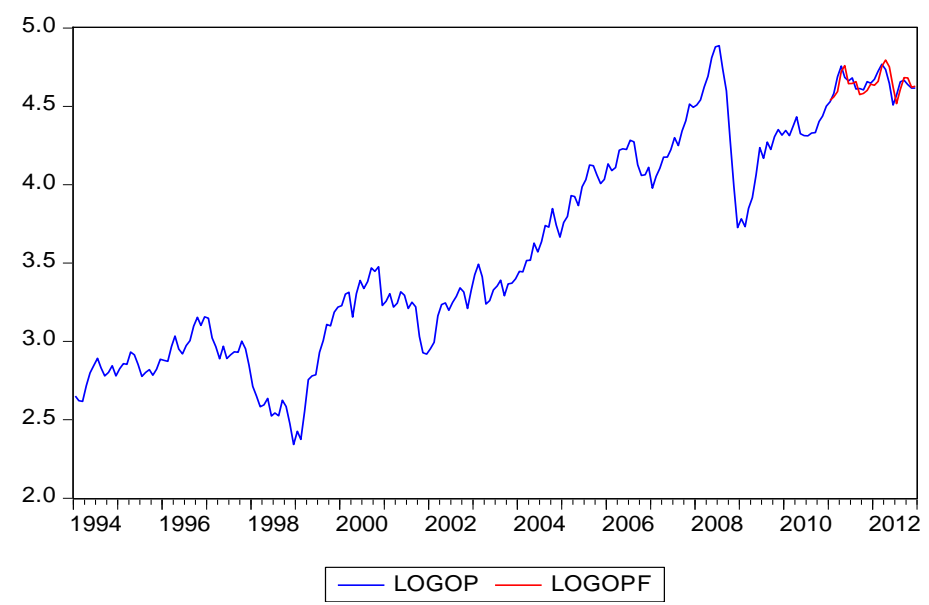

Figure $8 b$. Static line for $\log O P$

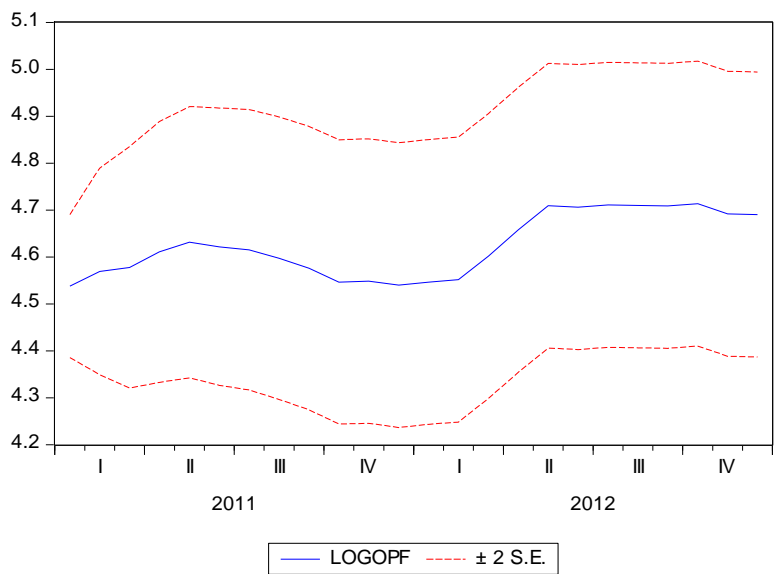

\begin{tabular}{|ll|}
\hline \multicolumn{2}{|l|}{ Forecast: LOGOPF } \\
Actual: LOGOP \\
Forecast sample: 2011M01 $2012 \mathrm{M} 12$ \\
Included observations: 24 & \\
Root Mean Squared Error & 0.098685 \\
Mean Absolute Error & 0.084208 \\
Mean Abs. Percent Error & 1.808338 \\
Theil Inequality Coefficient & 0.010643 \\
$\quad$ Bias Proportion & 0.056913 \\
Variance Proportion & 0.000308 \\
Covariance Proportion & 0.942779 \\
\hline
\end{tabular}

Figure 8c. Dynamic forecasting for LogOP 


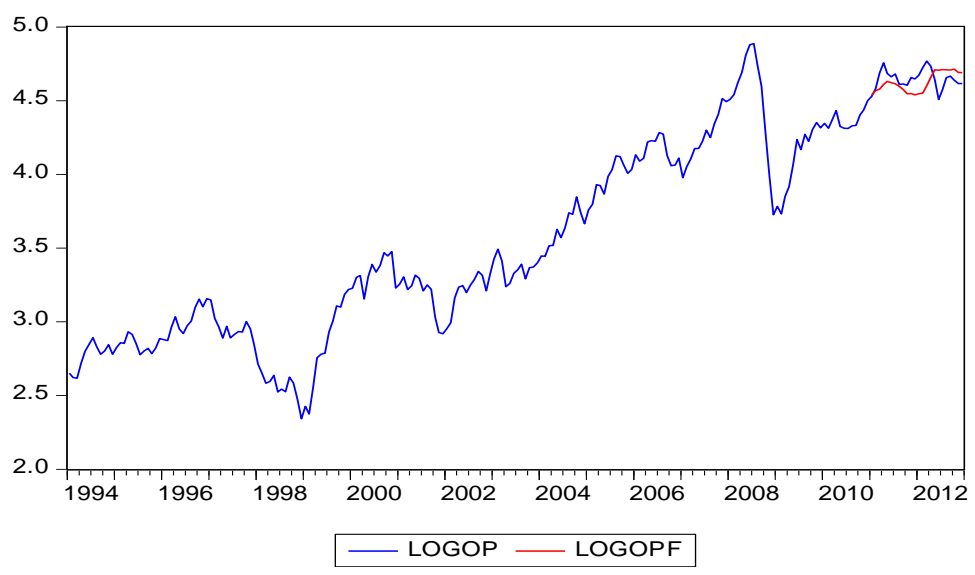

Figure 8d. Dynamic line for $\log O P$

\section{Conclusions}

The main aim of this study is to examine the impact of monetary policy shocks on output growth in South Africa and also forecast the predictive power of the model in assisting monetary authorities to cope with uncertainties in the future. After estimating the SVAR equation, the estimated model passes through structural imposition of restrictions, the variance decomposition analyses and several forecasting processes in order to forecast and predict South African data to achieve the objectives of the study.

The results from the variance decompositions of the macroeconomic variables are presented in Table 1 and Table 2. The results show that the interest rate and the commodity prices are the only variables found to be insignificant in explaining the variations in industrial output for all the months (Q1-Q4). The impacts of an unexpected change in the South African monetary policy on output (both industrial output and aggregate output) show a temporary impact of an upward and downward spring of monetary variables and global oil price shocks to the economy. The exchange rate, inflation and money are found to significantly impact output growth in the long run as well as the global oil price. The impact of interest rates to changes in industrial production remains below $1 \%$ in all periods. This may indicate that industrial producers in South Africa are not constrained by the cost of credit in their production of goods and services. Nonetheless, since oil price shock has an impact on economic activities and could negatively affect output growth, the policy recommendation suggests a continuous diversification of the economy and also that the monetary policy action should factor in the leading indicators of global prices and economic activity, taking into account the various channels, especially the exchange rate, for the forecast horizon (period).

Finally, the analysis from static and dynamic SVAR forecasting shows the analysis of trends in order to direct future trends and to direct policy response to stimulate output growth. Dynamic forecasting has a more robust result than static forecasting. It clearly brings out the growth patterns (increase and decrease) and can be justified and recommended to policymakers in calculating or in predicting the outcome of monetary policy actions for future development. However, the implication of the recommendation for the use of dynamic forecasting is the associated risk and uncertainty that might be central to its prediction, it's expected reliability and attributes (see Sohn, 1997), which are essential to its success and failure. Therefore, it will generally be a good practice if a combined (static and dynamic) forecasting technique is employed in order to compare and validate the degree of uncertainty attached to the model when forecasters are uncertain about the situation, uncertain about which method is most accurate, avoid large errors and draw from different sources of information in an attempt to stimulate output growth in the economy.

\section{References}

Amisano, G., \& Giannini, C. (1997). Model selection in Structural VAR analysis. In Topics in Structural VAR Econometrics. Springer Berlin Heidelberg. http://dx.doi.org/10.1007/978-3-642-60623-6_7

Amisano, G., \& Giannini, C. (2012). Topics in structural VAR econometrics. Springer Science \& Business Media.

Armstrong, J. S. (1989). Combining forecasts: The end of the beginning or the beginning of the end? International Journal of Forecasting, 5, 585-588. http://dx.doi.org/10.1016/0169-2070(89)90013-7

Barro, R. J., \& Gordon, D. B. (1981). A positive theory of monetary policy in a natural-rate model. NBER 
Working Paper No. 807. http://dx.doi.org/10.3386/w0807

Bates, J. M., \& Granger, C. W. (1969). The Combination of Forecasts, 20(4), 451-468. http://dx.doi.org/10.2307/3008764

Batten, D. S., \& Thornton, D. L. (1983). M1 or M2: Which is the better monetary target? Federal Reserve Bank of St. Louis Review, (Jun), 36-42.

Buckle, R. A., Kim, K., Kirkham, H., McLellan, N., \& Sharma, J. (2002). A structural VAR model of the New Zealand business cycle (p. 36). Wellington, New Zealand: The Treasury.

Clarida, R. H., Sarno, L., Taylor, M. P., \& Valente, G. (2003). The out-of-sample success of term structure models as exchange rate predictors: A step beyond. Journal of International Economics, 60(1), 61-83. http://dx.doi.org/10.1016/S0022-1996(02)00059-4

Clemen, R. T. (1989). Combining forecasting: A review and annotated bibliography. International Journal of Forecasting, 5, 559-583. http://dx.doi.org/10.1016/0169-2070(89)90012-5

Diebold, F. X., \& Li, C. (2006). Forecasting the term structure of government bond yields. Journal of Econometrics, 130(2), 337-364. http://dx.doi.org/10.1016/j.jeconom.2005.03.005

Dungey, M., \& Fry, R. (2009). The identification of fiscal and monetary policy in a structural VAR. Economic Modelling, 26(6), 1147-1160. http://dx.doi.org/10.1016/j.econmod.2009.05.001

Enders, W. (2004). Applied econometric time series (2nd ed.). Hoboken, NJ: John Wiley \& Sons.

Forni, M., Hallin, M., Lippi, M., \& Reichlin, L. (2003). Do financial variables help forecasting inflation and real activity in the euro area? Journal of Monetary Economics, 50(6), 1243-1255. http://dx.doi.org/10.1016/S0304-3932(03)00079-5

Friedman, M. (1997). Rx for Japan: Back to the future. Wall Street Journal, 17, A22.

Goodfriend, M. (1997). Monetary policy comes of age: A 20th century odyssey. FRB Richmond Economic Quarterly, 83(1), 1-22.

Harvey, C. R. (1989). Forecasts of economic growth from the bond and stock markets. Financial Analysts Journal, 45(5), 38-45. http://dx.doi.org/10.2469/faj.v45.n5.38

Hayashi, F. (1998). The Bank of Japan should set a base money target. Nikkei Daily, December 29. [In Japanese].

Hibon, M., \& Evgeniou, T. (2005). To combine or not to combine: Selecting among forecasts and their combinations. International Journal of $\quad$ Forecasting, $\quad 21, \quad 15-24$. http://dx.doi.org/10.1016/j.ijforecast.2004.05.002

Meltzer, A. (1998). Time to Print Money. Financial Times, July 17. Retrieved from https://scholar.google.co.za/scholar?q=Time+to+Print+Money.+\&btnG=\&hl=en\&as_sdt=0\%2C5

Menezes, L. M., Bunn, D. W., \& Taylor, J. W. (2000). Review of guidelines for the use of combined forecasts. European Journal of Operational Research, 190-204. http://dx.doi.org/10.1016/S0377-2217(98)00380-4

Mishkin, F. S. (2007). The economics of money, banking, and financial markets (6th ed.). Pearson education.

Ngalawa, H., \& Viegi, N. (2011). Dynamic effects of monetary policy shocks in Malawi. South African Journal of Economics, 79(3), 224-250. http://dx.doi.org/10.1111/j.1813-6982.2011.01284.x

Orphanides, A., \& Wieland, V. (2000). Efficient monetary policy design near price stability. Journal of the Japanese and International Economies, 14(4), 327-365. http://dx.doi.org/10.1006/jjie.2000.0452

Ping, X. (2004). The analysis of China's monetary policy in 1998-2002. Journal of Finance, 8, 1.

Raghavan, M., \& Silvapulle, P. (2008). Structural VAR approach to Malaysian monetary policy framework: Evidence from the pre-and post-Asian crisis periods. In New Zealand Association of Economics, NZAE Conference (pp. 1-32).

Sargent, T. J., \& Wallace, N. (1975). "Rational" expectations, the optimal monetary instrument, and the optimal money supply rule. The Journal of Political Economy, 83, 241-254.

Schumacher, C., \& Breitung, J. (2008). Real-time forecasting of German GDP based on a large factor model with monthly and quarterly data. International Journal of Forecasting, 24(3), 386-398. http://dx.doi.org/10.1016/j.ijforecast.2008.03.008 
Sharifi-Renani, H. (2010). A structural VAR approach of monetary policy in Iran. In International Conference On Applied Economics-ICOAE (p. 631).

Sohn, S. Y. (1997). Bayesian dynamic forecasting for attribute reliability. Computers \& Industrial Engineering, 33(3), 741-744. http://dx. doi.org/10.1016/S0360-8352(97)00236-2

Stock, J. H., \& Watson, M. W. (2002). Macroeconomic forecasting using diffusion indexes. Journal of Business \& Economic Statistics, 20(2), 147-162. http://dx.doi.org/10.1198/073500102317351921

Stock, J. H., \& Watson, M. W. (2004). Combination forecasts of output growth in a seven-country data set. Journal of Forecasting, 23(6), 405-430. http://dx.doi.org/ 10.1002/for.928

Taylor, J. B. (1997). Policy rules as a means to a more effective monetary policy (pp. 28-39). Palgrave Macmillan. http://dx.doi.org/10.1007/978-1-349-25382-1_2

Woodford, M. (2001). The Taylor rule and optimal monetary policy. The American Economic Review, 91(2), 232-237. http://dx.doi.org/10.1257/aer.91.2.232

\section{Appendix 1}

\section{Results of Variance Decomposition of all the Variables}

Table 1. Variance decomposition of logIP

\begin{tabular}{rccccccccc}
\hline Period & S.E. & LogIP & LogAG & EX & LogIF & IN & LogMS & LogCOMM & LogOP \\
\hline 1 & 0.008875 & 100.0000 & 0.000000 & 0.000000 & 0.000000 & 0.000000 & 0.000000 & 0.000000 & 0.000000 \\
2 & 0.013963 & 96.78180 & 0.030355 & 0.244777 & 1.726532 & 0.045114 & 0.197805 & 0.036831 & 0.936790 \\
3 & 0.016178 & 92.74746 & 0.455585 & 0.465166 & 3.428809 & 0.059522 & 0.192477 & 0.150533 & 2.500449 \\
4 & 0.016785 & 88.39537 & 2.185483 & 0.529521 & 4.619696 & 0.060791 & 0.181627 & 0.351888 & 3.675628 \\
5 & 0.017267 & 84.26276 & 5.692285 & 0.500922 & 4.843747 & 0.058531 & 0.173973 & 0.559361 & 3.908424 \\
6 & 0.018055 & 80.43667 & 9.984623 & 0.561241 & 4.478277 & 0.071127 & 0.198603 & 0.674008 & 3.595451 \\
7 & 0.018817 & 76.57377 & 14.00705 & 0.765910 & 4.125327 & 0.109127 & 0.370419 & 0.706871 & 3.341532 \\
8 & 0.019370 & 72.76509 & 17.36960 & 1.044421 & 3.904242 & 0.170862 & 0.811455 & 0.704047 & 3.230283 \\
9 & 0.019830 & 69.48337 & 19.85015 & 1.317502 & 3.725407 & 0.247533 & 1.557938 & 0.685951 & 3.132143 \\
10 & 0.020322 & 66.92833 & 21.43946 & 1.554027 & 3.557875 & 0.329092 & 2.535319 & 0.659643 & 2.996248 \\
11 & 0.020836 & 64.81180 & 22.45167 & 1.778640 & 3.422034 & 0.411189 & 3.640432 & 0.632243 & 2.851993 \\
12 & 0.021319 & 62.75630 & 23.23905 & 2.040187 & 3.316175 & 0.495122 & 4.819203 & 0.608923 & 2.725039 \\
\hline
\end{tabular}

Table 2. Variance decomposition of $\log A G$

\begin{tabular}{cccccccccc}
\hline Period & S.E. & LogIP & LogAG & EX & LogIF & IN & LogMS & LogCOMM & LogOP \\
\hline 1 & 0.003085 & 77.48383 & 22.51617 & $4.88 \mathrm{E}-27$ & $1.45 \mathrm{E}-32$ & $1.74 \mathrm{E}-30$ & $5.62 \mathrm{E}-28$ & $1.05 \mathrm{E}-29$ & $4.58 \mathrm{E}-29$ \\
2 & 0.005058 & 67.59600 & 30.76214 & 0.233060 & 0.788784 & 0.394393 & 0.004059 & 0.058007 & 0.163556 \\
3 & 0.006198 & 55.31778 & 41.64852 & 0.476512 & 1.196554 & 0.824647 & 0.145252 & 0.108812 & 0.281926 \\
4 & 0.006949 & 44.11716 & 51.60564 & 0.627367 & 1.161870 & 1.341528 & 0.756394 & 0.150134 & 0.239899 \\
5 & 0.007750 & 38.00727 & 56.37699 & 0.654785 & 0.934512 & 1.780316 & 1.817465 & 0.183258 & 0.245403 \\
6 & 0.008655 & 35.61838 & 57.15093 & 0.639709 & 0.834515 & 2.087411 & 3.053767 & 0.217635 & 0.397649 \\
7 & 0.009528 & 33.59041 & 57.34906 & 0.677145 & 0.855914 & 2.339638 & 4.372244 & 0.262062 & 0.553527 \\
8 & 0.010310 & 30.78635 & 58.17517 & 0.840124 & 0.869218 & 2.588930 & 5.832682 & 0.313409 & 0.594125 \\
9 & 0.011036 & 27.60037 & 59.17467 & 1.185978 & 0.821423 & 2.832936 & 7.485542 & 0.360122 & 0.538960 \\
10 & 0.011753 & 24.57400 & 59.68210 & 1.733694 & 0.737539 & 3.054348 & 9.346160 & 0.392526 & 0.479639 \\
11 & 0.012476 & 21.94962 & 59.40347 & 2.451849 & 0.654584 & 3.244352 & 11.40893 & 0.408955 & 0.478249 \\
12 & 0.013206 & 19.79598 & 58.35179 & 3.279454 & 0.586282 & 3.401386 & 13.63636 & 0.413820 & 0.534933 \\
\hline
\end{tabular}




\section{Appendix 2}

Detail Results of Static Forecasting of Variables

$$
\begin{aligned}
& \text {. pwcorr logip logipf } \\
& \text { | logip logipf } \\
& \text { logip | } 1.0000 \\
& \text { logipf } \mid 0.9410 \quad 1.0000
\end{aligned}
$$

. pwcorr logag logagf

$$
\begin{aligned}
& \text { | logag logagf } \\
& \text { logag |1.0000 } \\
& \text { logagf } \mid 0.9716 \quad 1.0000 \\
& \text {. pwcorr ex exf } \\
& \text { lex exf } \\
& \text { ex |1.0000 } \\
& \operatorname{exf} \mid 0.9470 \quad 1.0000
\end{aligned}
$$

$$
\begin{gathered}
. \text { pwcorr logif logiff } \\
\text { | logif } \quad \text { logiff } \\
\hline \begin{array}{c}
\text { logif } \mid 1.0000 \\
\text { logiff|0.9965 }
\end{array} \\
\hline
\end{gathered}
$$

. pwcorr in inf

$\mid$ in
In| 1.0000
Inf| $0.8385 \quad 1.0000$

$$
\begin{aligned}
& \text {. pwcorr logms logmsf } \\
& \text { |logms } \quad \operatorname{logmsf} \\
& \text { logms |1.0000 } \\
& \text { logmsf } \mid 0.9591 \quad 1.0000 \\
& \text {. pwcorr logcomm logcommf } \\
& \text { | logcomm logcommf } \\
& \text { logcomm |1.0000 } \\
& \text { logcommf } \mid 0.9201 \quad 1.0000
\end{aligned}
$$


. pwcorr logop logopf

\begin{tabular}{rr}
$\mid$ logop $\quad$ logopf \\
\hdashline $\operatorname{logop} \mid 1.0000$ \\
$\operatorname{logopf} \mid 0.6931 \quad 1.0000$
\end{tabular}

\section{Appendix 3}

\section{Detail Results of Dynamic Forecasting of Variables}

. pwcorr logip logipf

| logip $\quad$ logipf
logip | 1.0000
logipf $\mid 0.7509 \quad 1.0000$
. pwcorr logag logagf
| logag logagf
--------
logag |1.0000
logagf $\mid 0.8337 \quad 1.0000$

. pwcorr ex exf

$\begin{array}{cc}\mid \text { ex } & \text { exf } \\ \text { ex } \mid 1.0000 & \\ \operatorname{exf} \mid-0.8704 & 1.0000\end{array}$

. pwcorr logif logiff

|logif logiff

$\begin{array}{rr} & \\ \operatorname{logif} \mid 1.0000 & \\ \operatorname{logiff} \mid 0.9794 & 1.0000\end{array}$

. pwcorr in inf

\begin{tabular}{cc}
$\mid$ in & inf \\
\hline In|1.0000 & \\
Inf $\mid 0.8406$ & 1.0000
\end{tabular}

.pwcorr logms logmsf

| logms $\operatorname{logmsf}$

logms |1.0000

$\operatorname{logmsf} \mid 0.9540 \quad 1.0000$ 


\section{. pwcorr logcomm logcommf}

| logcomm logcommf

Logcomm|1.0000

logcommf|0.5171 1.0000

. pwcorr logop logopf

|logop logopf

--------------+-------------------

logop |1.0000

logopf |-0.1243 1.0000

\section{Copyrights}

Copyright for this article is retained by the author(s), with first publication rights granted to the journal.

This is an open-access article distributed under the terms and conditions of the Creative Commons Attribution license (http://creativecommons.org/licenses/by/3.0/). 